\title{
Chapter
}

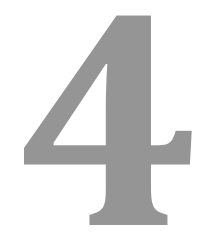

\section{BIODEGRADABLE POLYMERS FROM MONOMERS BASED ON VEGETABLE OILS}

Jingjiang Sun and Dirk Kuckling*

University of Paderborn, Chemistry Department, Warburger Str. 100, D-33098 Paderborn, Germany 


\section{Contents}

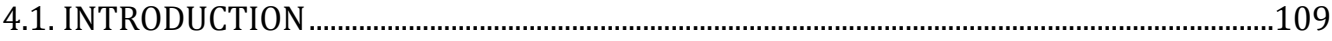

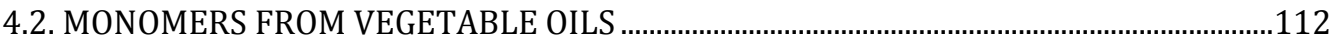

4.2.1. Monomers from vegetable oils via monoglyceride/alcoholysis process ..........112

4.2.2. Monomers from vegetable oils via ozonolysis process ...........................................113

4.2.3. Monomers based on epoxides from vegetable oils ...................................................117

4.2.4. Cyclic monomers for ring opening polymerization from vegetable oils ...........120

4.3. VEGETABLE OIL BASED POLYESTERS ……................................................................................122

4.4. VEGETABLE OIL BASED POLYANHYDRIDES .........................................................................

4.5. VEGETABLE OIL BASED POLYESTERAMIDES ……...............................................................129

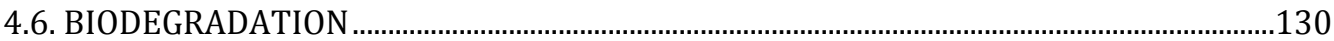

4.7. APPLICATION

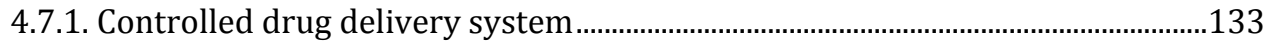

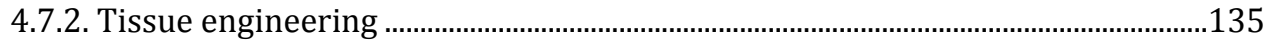

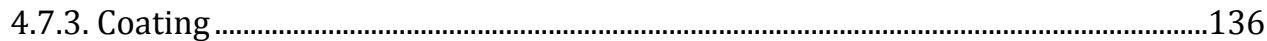

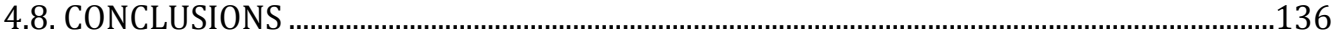

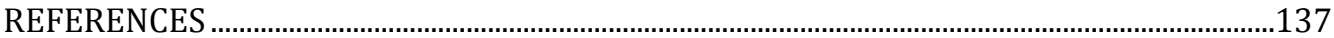




\subsection{INTRODUCTION}

The utilization of renewable raw materials as alternative resource to petroleum has recently attracted increasing attention. Nowadays, most polymeric materials are based on non-renewable fossil feedstocks and consume approximately $7 \%$ of all oil and gas worldwide used. Due to the limited petroleum reserve and from the view of sustainable development the urgent need is to develop polymeric materials from renewable resources [1-3]. Recently, a variety of polymers have been prepared from renewable raw materials, such as vegetable oils, wood, proteins and polysaccharides $[1,4]$. Compared to other renewable raw materials, vegetable oils have become more attractive in academic and industrial research due to their relatively low cost, low toxicity, worldwide availability, inherent biodegradability and versatile functionality $[1,4,5]$. According to the data released from Food and Agriculture Organization of the United Nations (FAO), the annual global production of vegetable oils rose from 149 million tons (in 2005/2006) to 210 million tons (in 2015/2016) in recent 10 years (an increase of $41 \%$ ). Industrial uses account for about $19 \%$ of the total production of vegetable oils $[6,7]$. Moreover, biodiesel converted from vegetable oils by pyrolysis, catalytic cracking and transesterification has been used as replacement of engine fuel.

Vegetable oils are mainly triglycerides which are esters of glycerol with three saturated or/and unsaturated fatty acids (Scheme 1). Fatty acids account for $95 \%$ of the total weight of triglycerides and their structures depend on the biological source and growing conditions $[1,4,5,8,9]$. A list of the most common fatty acids present in vegetable oils is summarized in Table 1.

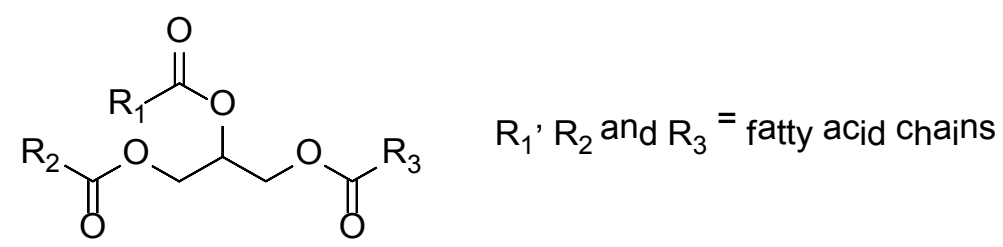

Scheme 1. General structure of a triglyceride molecule

As can be seen from Table 1, fatty acids are long-chain molecules with chain length between C8 and C22. The double bonds are located at different position along the chain in most of unsaturated fatty acids with a cis configuration, for example oleic acid (C18:1), linoleic acid (C18:2) and linolenic acid (C18:3) are the most common unsaturated fatty acid with 1,2 and 3 double bonds, respectively $[1,4,11,12]$. 
Table 1. Structures and formulas of the most common fatty acids $[1,8,10]$

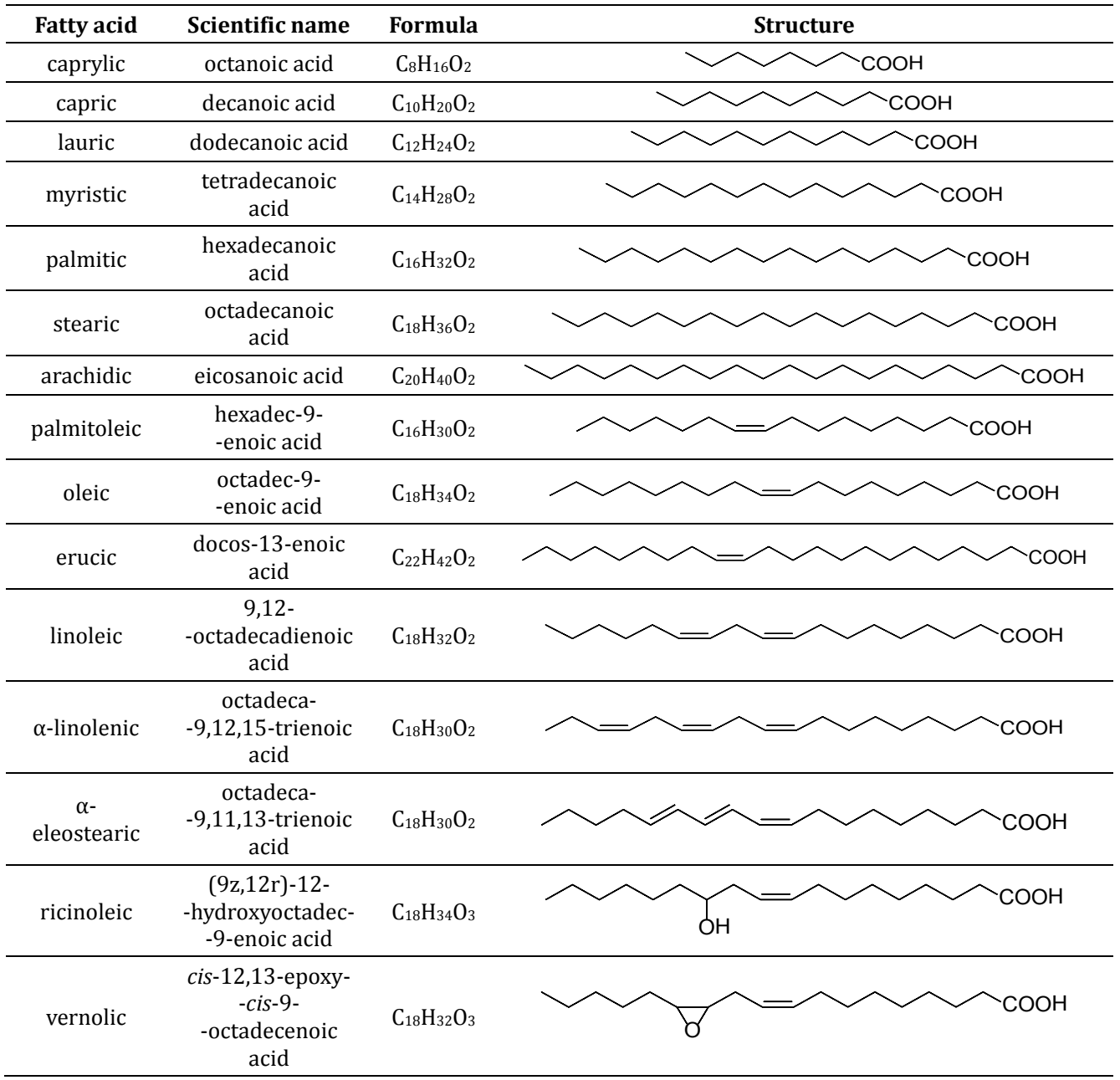

Table 2 represents the fatty acid compositions of different vegetable oils. The chemical and physical properties of vegetable oils depend strongly on the number of double bonds, fatty acid chain length and functionalities. The chain length (or averaged molar mass) of all the fatty acids in the vegetable oil can be determinated by the saponification value. The long-chain fatty acids found in vegetable oil have a low saponification value due to their relatively low number of ester groups per unit mass of the oil, while the short-chain fatty acids have a higher value [8]. The degree of unsaturation is measured by the iodine value. The iodine value is the mass of iodine in milligram that is consumed by the reaction of the double bonds in $100 \mathrm{~g}$ of the investigated vegetable oil. The higher the iodine values are, the higher the degree of unsaturation is. Depending on the iodine value, vegetable oils can be classified 
as drying oil (iodine value $>130$, e.g. linseed oil), semi-drying ( $90<$ iodine value $<130$ ) and non-drying oil (iodine value < 90, e.g. olive oil) $[1,8,11]$.

Triglycerides contain a variety of functional groups, such as double bonds, hydroxyl groups, epoxides and ester groups. By modifying these reactive sites, various easily polymerizable functional groups can be introduced in vegetable oil structure $[1,4,5]$. In this chapter, we will focus on the synthesis of monomers with functional groups from vegetable oils and the preparation of different kinds of biodegradable polymeric materials using these monomers. Properties, including chemical and physical properties, biocompatibility, application and biodegradability will be discussed in the flowing sections as well.

Table 2. Fatty acid composition of different vegetable oils and their properties[1,8,11,12]

\begin{tabular}{|c|c|c|c|c|c|c|c|c|}
\hline Name & $\begin{array}{l}\text { No. of } \\
\text { double } \\
\text { bonds }\end{array}$ & $\begin{array}{c}\text { Iodine } \\
\text { value } \\
\text { (mg of } \\
\text { I }_{2} / 100 \mathrm{~g} \text { ) }\end{array}$ & $\begin{array}{c}\text { Palmitic } \\
(16: 0)\end{array}$ & $\begin{array}{c}\text { Stearic } \\
(18: 0)\end{array}$ & $\begin{array}{c}\text { Oleic } \\
(18: 1)\end{array}$ & $\begin{array}{c}\text { Linoleic } \\
(18: 2)\end{array}$ & $\begin{array}{c}\text { Linolenic } \\
(18: 3)\end{array}$ & $\begin{array}{l}\text { Ricinoleic } \\
(18: 1+0 H)\end{array}$ \\
\hline canola & 3.9 & $105-120$ & 4.1 & 1.8 & 60.9 & 21.0 & 8.8 & - \\
\hline corn & 4.5 & $102-130$ & 10.9 & 2.0 & 25.4 & 59.6 & 1.2 & - \\
\hline cottonseed & 3.9 & $90-119$ & 21.6 & 2.6 & 18.6 & 54.4 & 0.7 & - \\
\hline groundnut & 3.4 & 80-106 & 11.4 & 2.4 & 48.3 & 31.9 & - & - \\
\hline linseed & 6.6 & $168-204$ & 5.5 & 3.5 & 19.1 & 15.3 & 56.6 & - \\
\hline olive & 2.8 & $75-94$ & 13.7 & 2.5 & 71.1 & 10.0 & 0.6 & - \\
\hline palm & 1.7 & $44-58$ & 42.8 & 4.2 & 40.5 & 10.1 & - & - \\
\hline rapeseed & 3.8 & $94-120$ & 4.0 & 2.0 & 56.0 & 26.0 & 10.0 & - \\
\hline sesame & 3.9 & $103-116$ & 9.0 & 6.0 & 41.0 & 43.0 & 1.0 & - \\
\hline soybean & 4.6 & $117-143$ & 11.0 & 4.0 & 23.4 & 53.3 & 7.8 & - \\
\hline sunflower & 4.7 & $110-143$ & 5.2 & 2.7 & 37.2 & 53.8 & 1.0 & - \\
\hline castor & 3.0 & $82-90$ & 1.5 & 0.5 & 5.0 & 4.0 & 0.5 & 87.5 \\
\hline
\end{tabular}




\subsection{MONOMERS FROM VEGETABLE OILS}

\subsubsection{Monomers from vegetable oils via monoglyceride/alcoholysis process}

There are various techniques to obtain polyols from vegetable oils. The most commercially used method is the monoglyceride process. In this route, monoglycerides can be obtained by modification of the triglyceride ester groups through alcoholysis with glycerol in the presence of a base or acid catalyst. Scheme 2 represents the chemical reaction for vegetable oil alcoholysis [10].

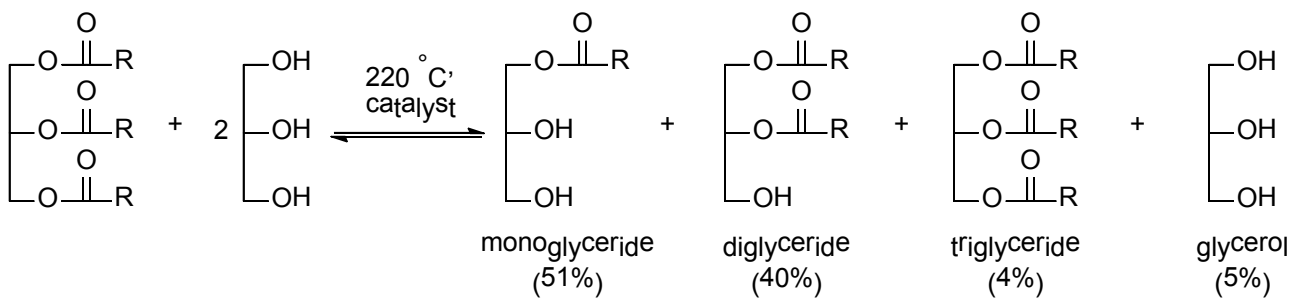

Scheme 2. Alcoholysis of vegetable oils with glycerol [10]

The alcoholysis is a reversible ester interchange reaction when it is carried out homogeneously. According to the Le Chatelier's principle, use of an excess of glycerol over the 2 moles theoretically required will shift the equilibrium to the right, thus resulting higher total amount of monoglycerides [13]. The major challenge of this reaction is enhancing the solubility of the hydrophilic glycerol in initial hydrophobic vegetable oil or in subsequent fat-like phases. Only about $4 \%$ glycerol can dissolve in common vegetable oil at room temperature. To overcome this incompatibility, it will be necessary to conduct this reaction at elevated temperature $\left(220-240^{\circ} \mathrm{C}\right)$ in the presence of a catalyst [13]. Another reason for the high reaction temperature is to promote the formation of monoglycerides, while diglycerides are preferably formed at low temperatures. For this reason, to prevent the reversed reaction at the end of alcoholysis, the reaction mixture must be rapidly cooled to a low temperature (about $15^{\circ} \mathrm{C}$ ). The excess unreacted glycerol is then separated and removed as a lower layer. Can et al. found that rapid cooling of the reaction mixture with high speed stirring can improve the yield of monoglycerides significantly [14]. The final composition after removing excess glycerol can be determined by different methods, such as thin layer chromatography (TLC), gas chromatography (GC) or high performance liquid chromatography (HPLC). Consequently, the resulting product mixture after alcoholysis with glycerol consists typically of $51 \%$ monoglyceride, $40 \%$ diglyceride, $4 \%$ triglyceride and $5 \%$ glycerol [10].

Usually, the alcoholysis of vegetable oil is carried out by use of catalysts. In the absence of catalyst, a reaction temperature of $280^{\circ} \mathrm{C}$ or higher is required and the products have dark color and high viscosity. Basic catalysts are used 
preferably in the alcoholysis reaction. A variety of basic catalysts has been studied, such as elemental metal ( $\mathrm{Na}, \mathrm{K}, \mathrm{Sn}$ ), metal oxides ( $\mathrm{CaO}, \mathrm{SrO}, \mathrm{PbO}$ ), metal hydroxides $\left(\mathrm{LiOH}, \mathrm{NaOH}, \mathrm{KOH}, \mathrm{Ca}(\mathrm{OH})_{2}\right)$, metal salt of weak acids (calcium octate), metal alkoxides $(\mathrm{NaOMe}, \mathrm{NaOEt}, \mathrm{NaO} \mathrm{Bu}$ ) and organotin compound (dibutyltin oxide (DBTO)). Among these catalysts, sodium alkoxides, $\mathrm{LiOH}, \mathrm{PbO}$ and DBTO showed highest catalytic activities [10]. For industrial use $\mathrm{NaOH}$ and $\mathrm{KOH}$ are the preferred catalysts due to their relatively high efficiency and low prices. One disadvantage is that the used catalysts must be neutralized and removed from product mixture because the residual catalyst cause reversion. Moreover, the trace of catalyst can also lead to soapy taste, poor color stability and foaming problems for use of food emulsifiers. The removal of catalyst is usually conducted as follow: the basic catalysts are firstly neutralized with phosphoric acid and the neutralization products, metal phosphate, are absorbed with clays [13]. In addition, oxygen and traces of water have been reported to decrease the reaction rate. Carbon dioxide in the air can convert metal catalysts to carbonates. Thus the alcoholysis reaction should be carried out under nitrogen atmosphere to avoid oxidation and color problems $[10,13]$.

Similarly, besides using glycol alcoholysis of vegetable oils is often conducted with pentaerythrol [15]. Palm [16], soybean [14,15,17], tung [16], rapeseed [18], jatropha [18], castor [15], rubber seed [19], melon seed [19], mahua [20] and Nahar seed [21,22] oils have been used as raw materials to prepare monoglycerides via alcoholysis process. In most cases, the vegetable oil based monoglycerides are further modified with different anhydride (glutaric, phthalic, maleic and succinic anhydrides), followed by polycondensation to form various alkyd resins.

\subsubsection{Monomers from vegetable oils via ozonolysis process}

Ozone molecule $\left(\mathrm{O}_{3}\right)$ includes three oxygen atoms with a delta positive and a delta negative electric charge. It is very unstable and has a short half-life. Therefore, ozone must be generated on-site by corona-discharge, UV-light, cold plasma or electrolysis method of oxygen containing feed gas in an ozone generator. The most common method for industrial and laboratorial use is corona discharge method. Ozone is produced in the corona as a direct result of electrical discharge. The electrical discharge causes the cleavage of the stable $\mathrm{O}_{2}$ bonds to form two oxygen radicals. Ozone molecule can be consequently produced by combination of an oxygen radical with oxygen molecule [23-25].

$$
3 \mathrm{O}_{2} \text { (g) } \stackrel{\text { electricity }}{\longrightarrow} 2 \mathrm{O}_{3}(\mathrm{~g}) \Delta \mathrm{H}^{\circ}=285 \mathrm{~kJ}
$$

To diffuse the spark into a corona and maintain the electrical discharge, a dielectric is present. The dielectric may be made from glass, ceramic, quartz or 
mica. Dried ambient air (21\% oxygen) or dried pure oxygen can be used as feed gas. The generated ozone concentration is strongly dependent on the oxygen concentration in feed gas. The higher the oxygen content in feed gas is, the higher the ozone concentration generated is. Advantages of the corona discharge technique are cost-effective, sustainable and higher ozone production [25].

The strong oxidizability of ozone is referred to its very high oxidation potential of $2.07 \mathrm{~V}$ in comparison to other oxidants (Table 3). Based on the high oxidizability, ozone has been widely used in industry including disinfection in pools and spas, wastewater treatment, producing chemicals via chemical reactions, food process and many more [26].

Table 3. Redox potential of oxidants [27]

\begin{tabular}{cc}
\hline Substance & Potential (V) \\
\hline fluorine $\left(\mathrm{F}_{2}\right)$ & 2.87 \\
\hline hydroxy radicals $(\cdot \mathrm{OH})$ & 2.86 \\
\hline atomic oxygen $(\mathrm{O})$ & 2.42 \\
\hline ozone $\left(\mathrm{O}_{3}\right)$ & 2.07 \\
\hline hydrogen peroxide $\left(\mathrm{H}_{2} \mathrm{O}_{2}\right)$ & 1.78 \\
\hline chlorine $\left(\mathrm{Cl}_{2}\right)$ & 1.36 \\
\hline chlorine dioxide $\left(\mathrm{ClO}_{2}\right)$ & 1.27 \\
\hline oxygen molecule $\left(\mathrm{O}_{2}\right)$ & 1.23 \\
\hline
\end{tabular}

As mentioned above, the unsaturated triglycerides contain a number of carbon-carbon double bonds. The presence of double bonds provides the possibility to introduce various functional groups by chemical reactions, such as hydrogenation, epoxidation, ozonolysis or olefin metathesis [28]. However, the polymeric materials prepared from monomers based on olefin metathesis are usually non-biodegradable. Thus, this process will be not described in this chapter. This section is focused on the oxidation of double bonds in vegetable oils by ozonolysis process. Ozonolysis is an important and effective route to cleave carbon-carbon double bonds to give compounds with primary alcohols, aldehydes and carboxylic acids (Scheme 3). 


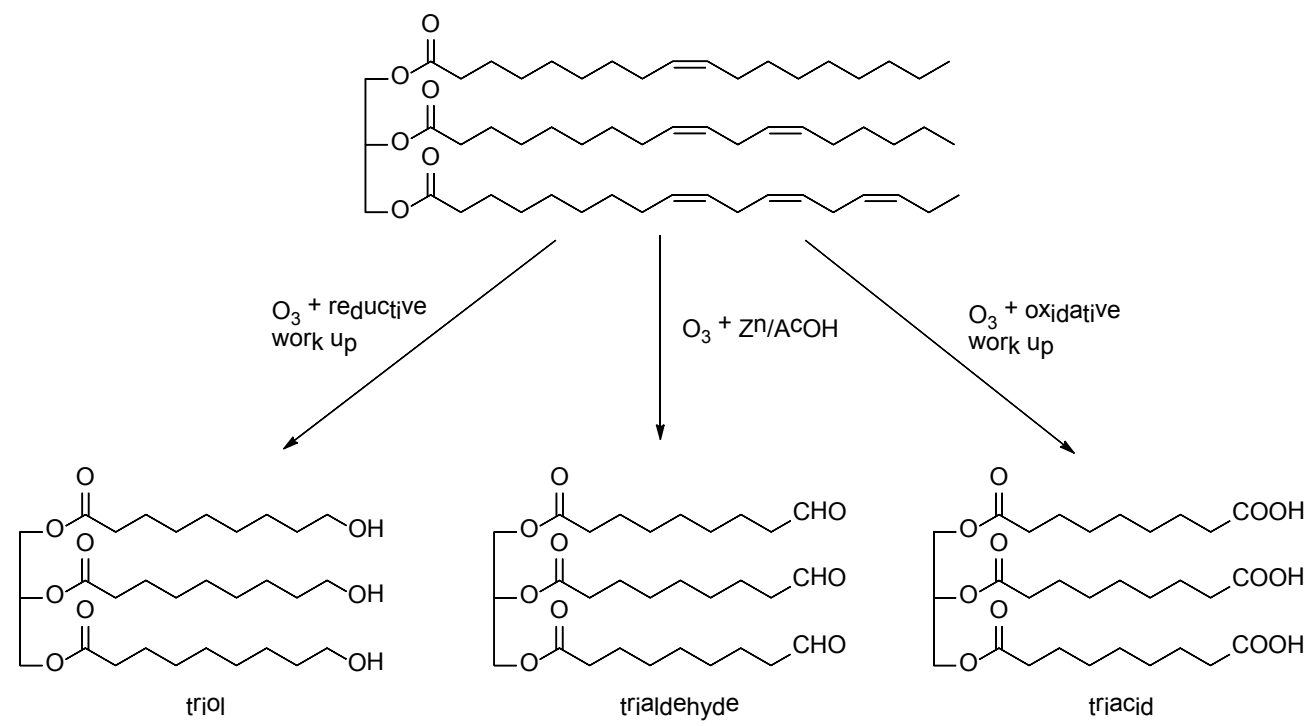

Scheme 3. Ozonation of soybean oil to give triol, trialdehyde and triacid

The best established mechanism is given in Scheme 4. The ozonolysis of double bonds begins with the formation of a five-member ring named molozonide (b) via a 1,3-dipolar cycloaddition of ozone with the double bond. Due to the high instability of the two $\mathrm{O}-\mathrm{O}$ bonds the molozonide decomposes immediately to yield an aldehyde (c) and a carbonyl oxide (d). This decomposition reaction is referred to as a 1,3-dipolar cycloreversion. The carbonyl oxide will react further in one of two ways depending on the used solvent.

In protic solvent (e.g. $\mathrm{MeOH}$ or other alcohol solvents) the carbonyl oxide is captured by solvent molecule to form a hydroperoxide (k). Conversely, in the presence of aprotic solvent (e.g. dichloromethane) the carbonyl oxide (d) undergoes a cycloaddition to give the more stable secondary ozonide (e), which is named Staudinger ozonide. If the carbonyl oxide is formed along with a ketone instead of an aldehyde, a cycloaddition of two carbonyl oxide to an extremely explosive dimeric peroxide (1,2,4,5-tetroxane) (f) preferably happens. Moreover, the formation of the secondary aldehyde (h) via dimerization of two carbonyl oxide and followed decomposition has been also reported [29-33]. 


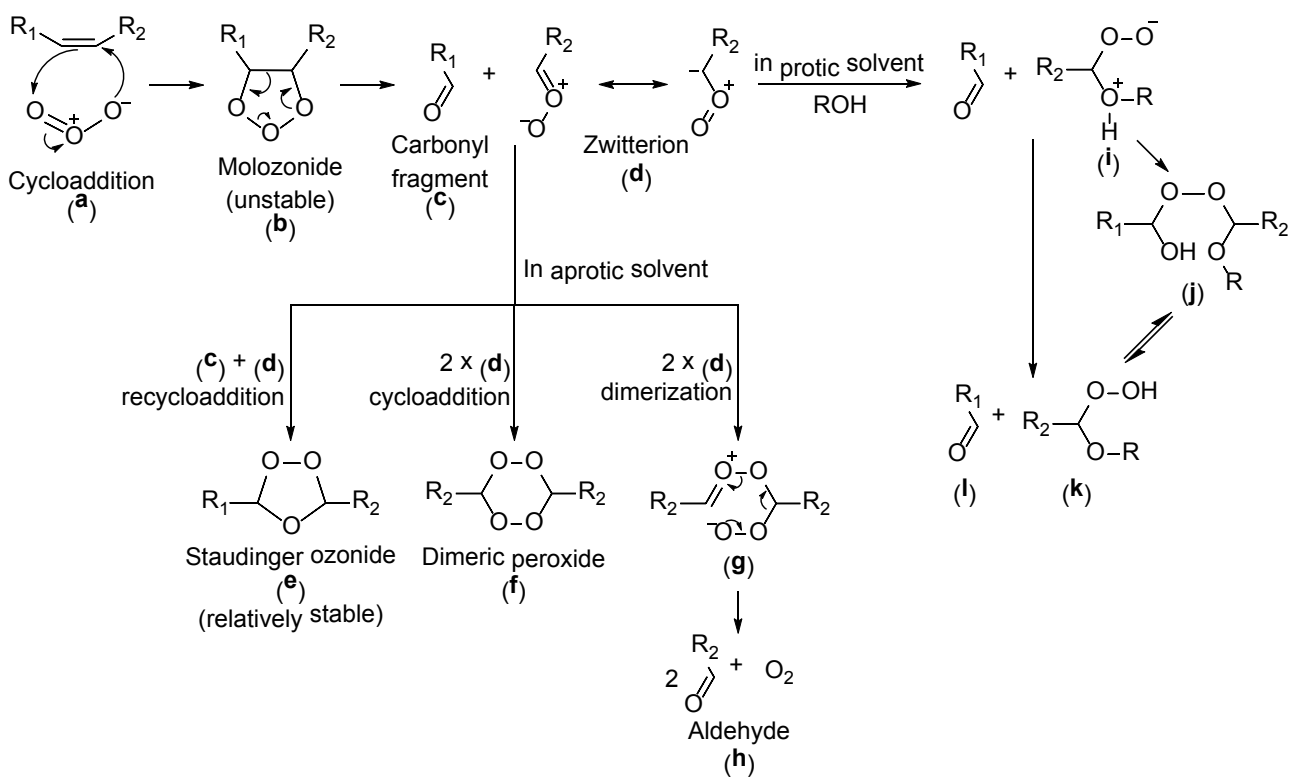

Scheme 4. Proposed ozonation mechanisms of double bonds [34]

Triols have been prepared by ozonation of different vegetable oils, such as castor, soybean, canola oils and trilinolein. Kong et al. has used a two-step ozonolysis- and hydrogenation-based technology to synthesize polyols from canola oil. In the first step, canola oil was ozonized in ethyl acetate at $10^{\circ} \mathrm{C}$ resulting the Staudinger ozonide and followed reduced with zinc at room temperature to give a trialdehyde, which was then hydrogenated by Raney nickel as catalyst at $70^{\circ} \mathrm{C}$ and 100 psi (Scheme 5) [35].

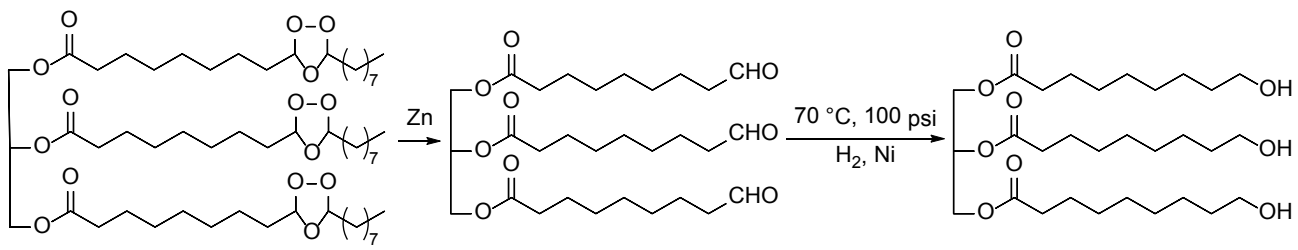

Scheme 5. Two-step ozonolysis of canola oil [35]

Petrović et al. [36,37] has produced triols from castor, soybean, canola oils and trilinolein by a one-step ozonolysis in methanol/dichloromethane. Unsaturated triglycerides were firstly converted to mixture of aldehydes and hydroperoxides. They were reduced in the next step to hydroxyl groups using $\mathrm{NaBH}_{4}$ as reducing agent. Low molecular weight byproducts, such as monoand diols were removed under vacuum (Scheme 6). 


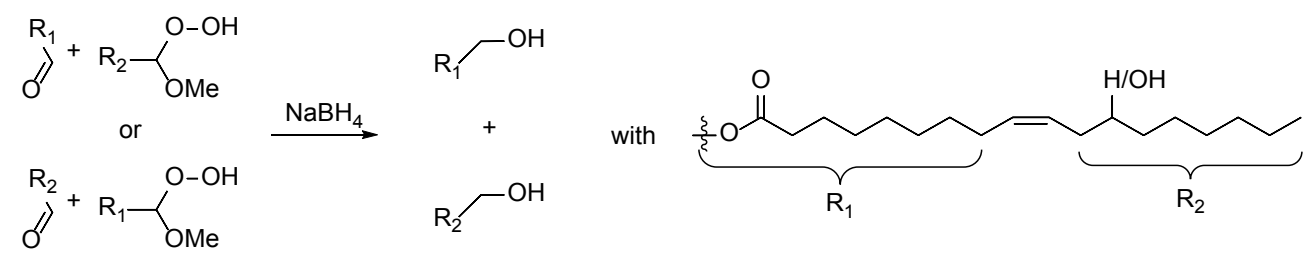

Scheme 6. Ozonolysis of vegetable oil in methanol/dichloromethane [38]

Pryde et al. [38] described a relatively simple method of preparing trialdehydes from triolein under different conditions. The triglyceride was ozonized in methanol/dichloromethane $(4: 5 \mathrm{v} / \mathrm{v})$ at $-4{ }^{\circ} \mathrm{C}$ and reduced with zinc powder and acetic acid at room temperature (Scheme 7). The trialdehyde oil was obtained by removal of zinc salt, unreacted acetic acid and volatile low molecular weight aldehydes to give a light yellow viscous liquid with yield of $85 \%$.

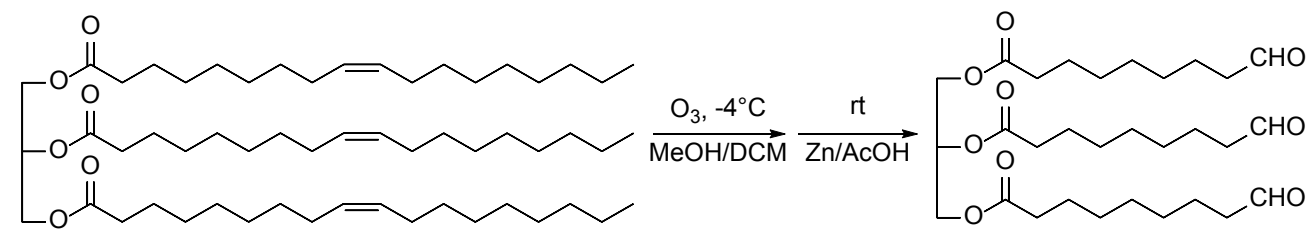

Scheme 7. Preparation of trialdehyde from triolein [38]

\subsubsection{Monomers based on epoxides from vegetable oils}

Vernonia oil has attracted significant attention for preparation of polymeric materials. The vernonia oil is extracted from the seeds of Vernonia galamensis plants. The oil consists of 70-80 \% vernolic fatty acid, which contains an epoxy group in the $12^{\text {th }}$ and $13^{\text {th }}$ positions (Scheme 8). Due to the presence of the three epoxy groups in the triglyceride structure, the Vernonia oil can react as trifunctional monomer with other multi-functional regents, such as dibasic acids, diamines, to give crosslinked polymers. The resulting polymers are soft elastomers with low glass temperature $\left(T_{\mathrm{g}}\right)$ and can be used to form interpenetrating polymer networks (IPNs) with other polymers [39-41].

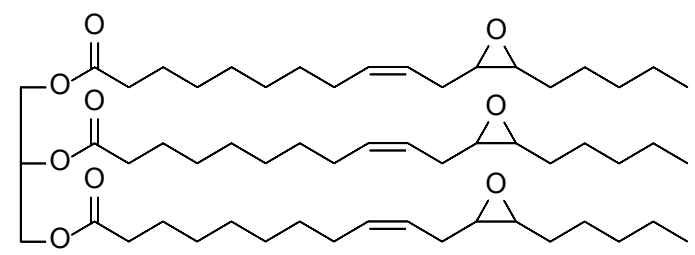

Scheme 8. Structure of Vernonia oil [40] 
The unsaturated fatty acids in vegetable oils can undergo epoxidation to introduce epoxy groups, which can be utilized by ring-opening reaction to give a variety of polymerizable functional groups $[42,43]$. The synthetic route to epoxidized soybean oil (ESBO) is shown in Scheme 9 [44]. The carbon-carbon double bonds in glycerides are converted to epoxide groups by reaction with a peroxy acid. ESBO is nowadays commercially available [45].

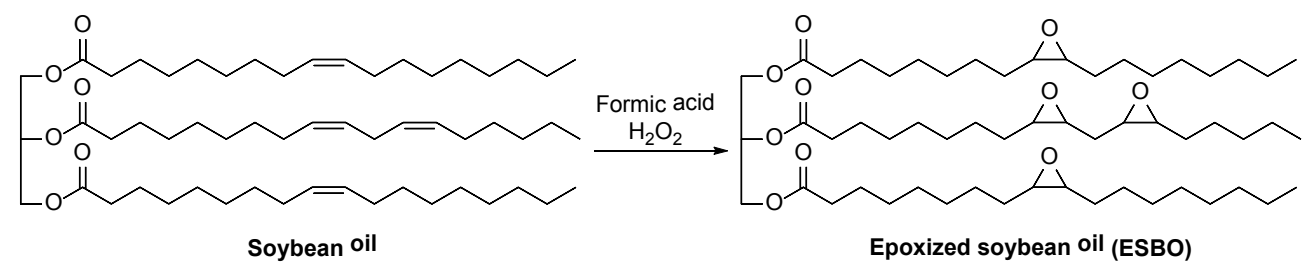

Scheme 9. Synthetic route of epoxidized soybean oil (ESBO) [44]

A series of nucleophilic regents can be used to open the epoxy group to yield a new functional group and a hydroxyl group from epoxy oxygen atom. Scheme 10 illustrates some examples for modification of epoxy groups. Acrylation of ESBO has been extensively studied. The acrylated epoxidized soybean oil (AESO) is obtained from the reaction of ESBO with acrylic acid (a) [44]. As seen in route $b$, a multiaziridine-containing acrylated epoxidized soybean oil (AESO-AZ) was synthesized by grafting 2-methylaziridine onto ESBO through a Michael addition [46]. Lu et al. reported a further modification based on AESO to introduce carboxylic acid groups by the reaction of residual epoxy groups or hydroxyl groups with maleic anhydride (c) [44]. 


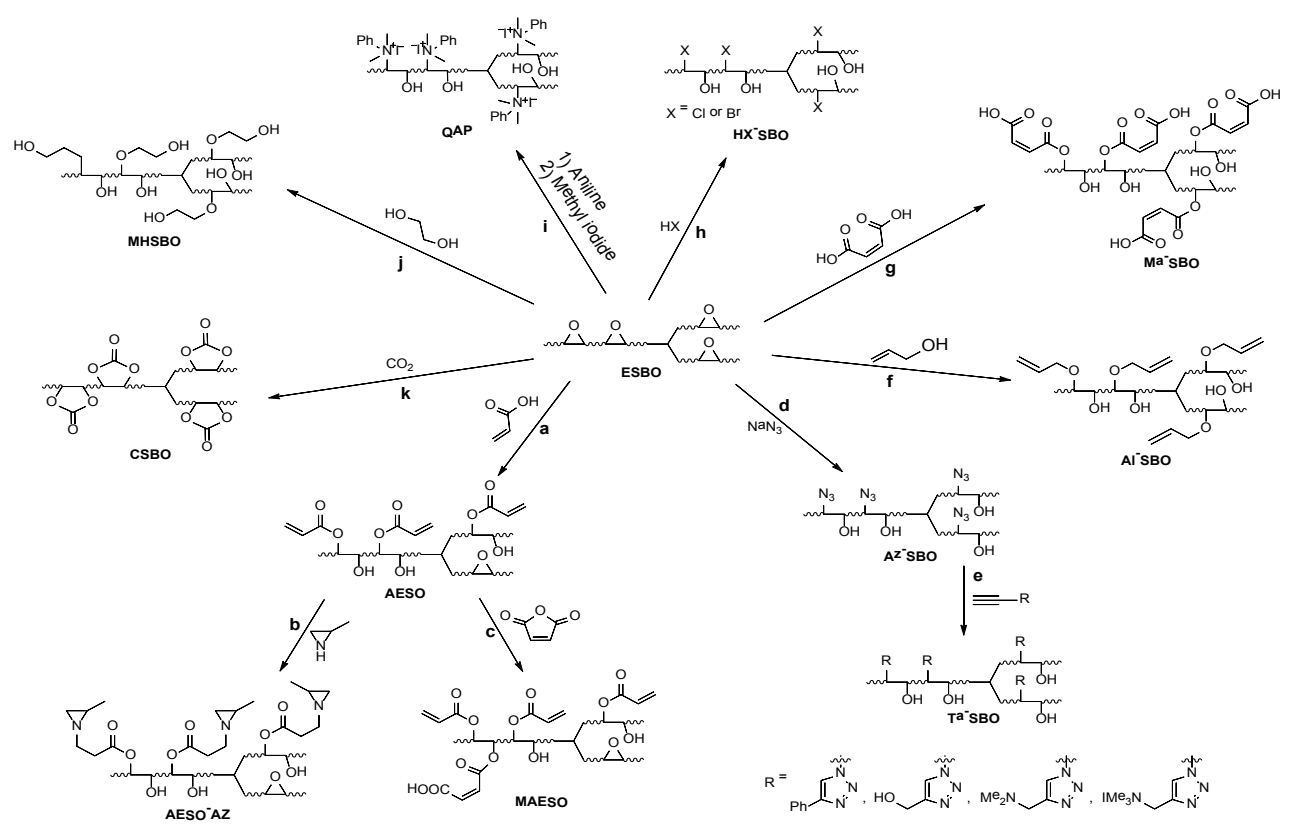

Scheme 10. Synthesis of monomers with different functionalities by modification of ESBO

Recently, azide-containing polyols from soybean oil (Az-SBO) have been prepared from ESBO reacted with sodium azide (d) [45,47]. The Az-SBO products can be further subjected to the cycloaddition with different alkynes through click chemistry (e). These polyols were used to produce polymeric coatings with biocidal activity [45]. Other functional groups such as alcohols, double bonds in side chains, carboxylic acid or halogen groups have been introduced into vegetable oil structures though the ring opening reaction with alcohols (e.g. allyl alcohol (f, Al-SBO) [48], ethylene glycol (j, MHSBO) [49]), maleic acid (g, Ma-SBO) [50] and hydrogen halides (e.g. $\mathrm{HCl}$ and $\mathrm{HBr}$ (h, HX-SBO) [51]), respectively, and utilized for further application. The treatment of ESBO with aniline, followed by methylation with methyl iodide allowed the synthesis of quaternary ammonium salts containing polyol (i, QAP) with antibacterial property [52]. Djalilian et al. described a novel method to convert ESBO to carbonated soybean oil (CSBO) using tetrabutylammonium bromide (TBAB)/calcium chloride as catalyst under ambient pressure of $\mathrm{CO}_{2}$ gas $(\mathrm{k})$ [53]. 


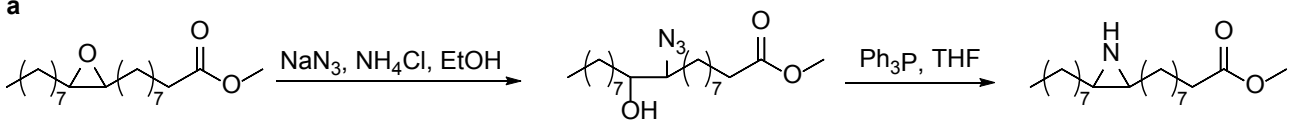

b

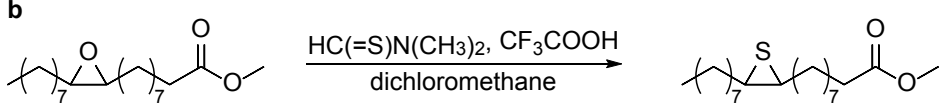

Scheme 11. Synthesis of aziridine [54] and episulfide [55] from epoxidized methyl oleate

Besides ESBO, epoxidized methyl oleate has been transformed to aziridine [54] and episulfide [55] (Scheme 11). These compounds are interesting intermediates in the synthesis of heterocyclic and highly functionalized substances [42].

\subsubsection{Cyclic monomers for ring opening polymerization from vegetable oils}

$\omega$-Hydroxy fatty acids are a class of straight long-chain aliphatic organic compounds with carboxylic acid and hydroxyl functionalities located at both ends of the fatty acid chain. The $\omega$-hydroxy fatty acids have been attracted much attention for preparation of mixed diesters, cosmetic formulations and phospholipids [56]. Ricinoleic acid (Table 1, row 14) is a common $\omega$-hydroxy fatty acid obtained by hydrolysis of castor oil with a carboxylic acid group in the $1^{\text {st }}$ position and a hydroxyl group in the $12^{\text {th }}$ position. Domb and coworkers have reported the synthesis of macrolactone mixture (Scheme 12, 1RM-6RM) from ricinoleic acid as raw material. According to the GPC analysis 1RM to 4RM could be separated by gel chromatography to the individual lactones. The compositions of macrolactones mixture were strongly dependent on reaction concentrations. Higher reaction concentrations led to preferably larger rings (4RM to 6RM). However, ring opening polymerization of these macrolactones was difficult and resulted only oligomers [57].

Narine et al. demonstrated a synthetic route for the preparation of lactone from methyl oleate. The methyl oleate was ozonolysed, hydrogenated and saponified to be converted to 9-hydroxynonanoic acid. When di-2-thioyl carbonate was used as coupling regent and hafnium (IV) trifluoromethanesulfonate ( $\left.\mathrm{Hf}(\mathrm{OTf})_{4}\right)$ as catalyst, a monolactone product was obtained. The synthesis of dilactone with high yield (98\%) was accomplished by using hafnium chloride $\left(\mathrm{HfCl}_{4}\right)$ as catalyst $[56,58]$. 

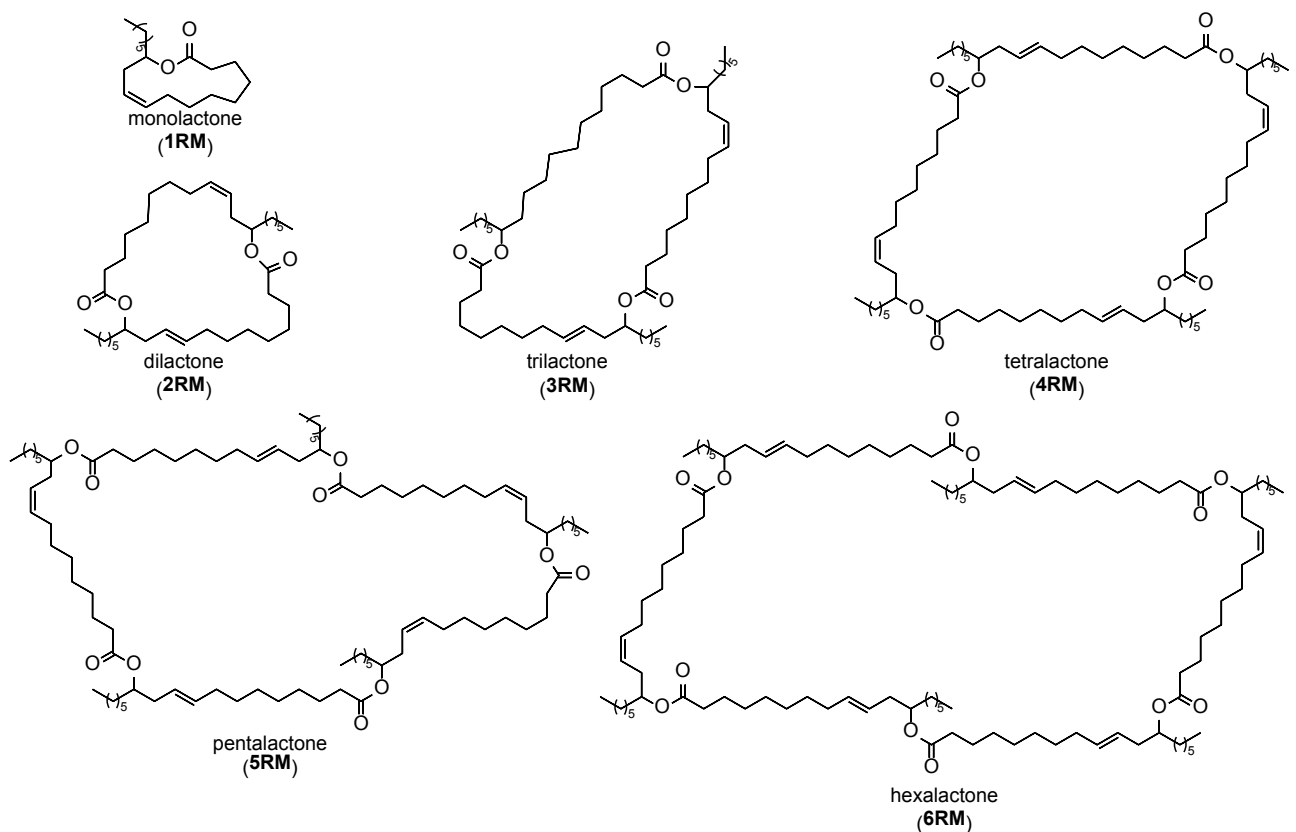

Scheme 12. Synthesis of cyclic macrolactones from castor oil [57]

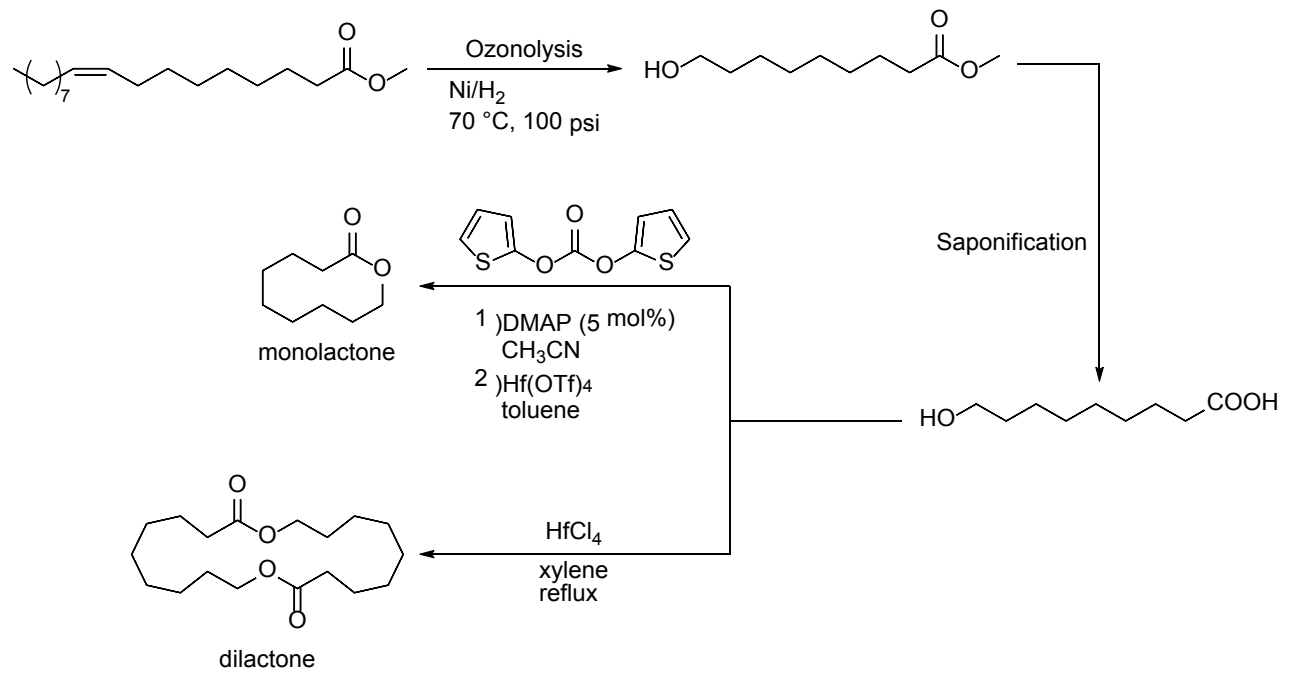

Scheme 13. Synthetic route of monolactone and dilactone from methyl oleate $[56,58]$ 


\subsection{VEGETABLE OIL BASED POLYESTERS}

Polyesters are the most widespread used biodegradable polymeric materials for drug carrier and tissue engineering. Polyesters can be synthesized either by ring opening polymerization (ROP) of cyclic ester monomers or polycondensation of two multifunctional monomers. Condensation polymerization is a polymerization process by which two molecules (monomer, oligomer or polymer molecules) are linked together by generating a new functional group with elimination of a small molecule resulting elongation of polymer chains. Polyester can be synthesized by condensation polymerization with the elimination of water molecules in each condensing step (Scheme 14a). ROP of cyclic ester monomers is one of the most effective methods to obtain homo- or copolyesters with a high molar mass and low dispersity under milder reaction conditions in comparison to condensation polymerization (Scheme 14b) [59,60]. Metallic compounds [61], guanidine based catalysts [62-65], strong acids [66-68], phosphazene [69], $N$-heterocyclic carbine $[70,71]$, bifunctional thiourea-amine $[63,72,73]$ and enzyme [74-76] have been applied as catalysts to the controlled ROP of cyclic esters.

a

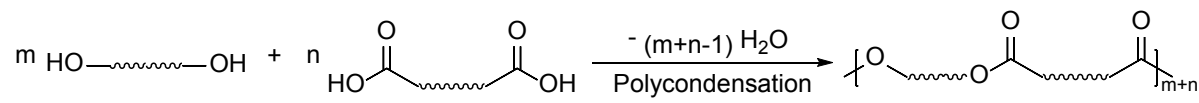

b

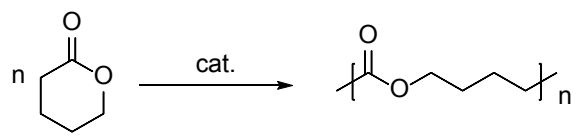

Scheme 14. a) Typical polycondensation of synthesis of polyester; b) ring-opening polymerization of a lactone

Vegetable oil based polyester resins (alkyds) were mainly obtained by polycondensation from monoglyceride with dicarboxylic acid anhydride. The properties of the polyesters can be adjusted by using different type of dicarboxylic anhydride and monoglyceride/anhydride feed ratios. When dicarboxylic acid anhydrides with rigid structures are used, polyesters with higher glass transition temperatures and cross-linking densities will be obtained. The synthetic route is shown in Scheme 15.

Monoglyceride from Nahar seed oil has been used for preparation of polyester resins by reaction with phthalic or maleic anhydride at high temperature. Investigation of the chemical resistance showed, that the resulting polyester films were highly resistant to dilute $\mathrm{HCl}$ acid, $\mathrm{NaCl}$ solution and distilled water, while they could be hydrolyzed under basic conditions [22]. 
<smiles>[R]C(=O)OCC(COC([Y])=O)OC(=O)[R17](C)CC(C)C</smiles><smiles>CC1=CCC2C(=O)OC(=O)C2CC1</smiles><smiles>O=C1OC(=O)c2ccccc21</smiles><smiles>O=C1OC(=O)C2CC=CCC12</smiles><smiles>CC1CCC2C(=O)OC(=O)C2C1</smiles><smiles>Cc1cc2c(cc1C)C(=O)OC2=O</smiles>

etc.

Scheme 15. Synthesis of polyesters from monoglyceride and dicarboxylic acid anhydride
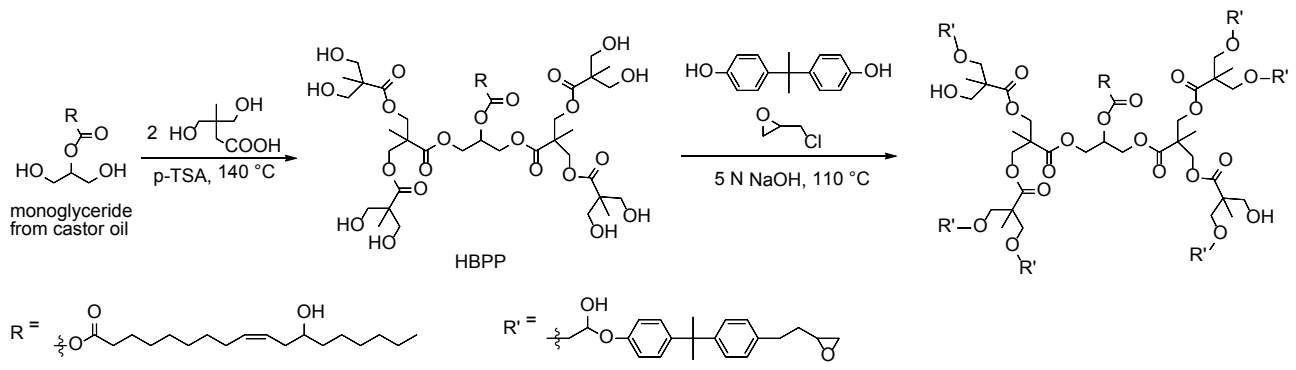

Scheme 16. Synthesis of castor oil monoglyceride based hyperbranched epoxy thermoset [77]

Recently, a hyperbranched polyester polyol (HBPP) was synthesized by Karak and coworkers from castor oil based monoglyceride and bis(hydroxy methyl) propionic acid (Bis-MPA) (Scheme 16). The HBPP was reacted with bisphenol A and glycidyl ether epoxy to form a hyperbranched epoxy with a polyester backbone. This castor oil monoglyceride based resins could be used as thermosets with excellent toughness, flexibility and elasticity, and they were relatively thermostable and biodegradable [77].

Polynonanolactones (PNLs) were successfully prepared by employing the ROP of castor oil based monolactone and dilactone (Scheme 13) with tin(II) 2-ethylhexanoate as catalyst. The number averaged molar mass of synthesized PNLs were varied from 6000 to $13000 \mathrm{~g} \mathrm{~mol}^{-1}$ with dispersities below 1.40 . The melting points $\left(T_{\mathrm{m}}\right)$ of these polylactones are about $50^{\circ} \mathrm{C}$ and increased slightly with increasing molar mass [58]. 
Castor oil is obtained from the seeds of castor oil plant (Ricinus communis) and has been widely used for preparation of various biodegradable polyesters. Compared to other vegetable oils, castor oil is a special monomer for polymerization, because it contains about $90 \%$ bifunctional ricinoleic acid with a double bond between the $9^{\text {th }}$ and $10^{\text {th }}$ position and an inherent hydroxyl group in the $12^{\text {th }}$ position. The ricinoleic acid can be produced by hydrolysis of castor oil [78]. The structures of castor oil and ricinoleic acid are shown in Scheme 17.
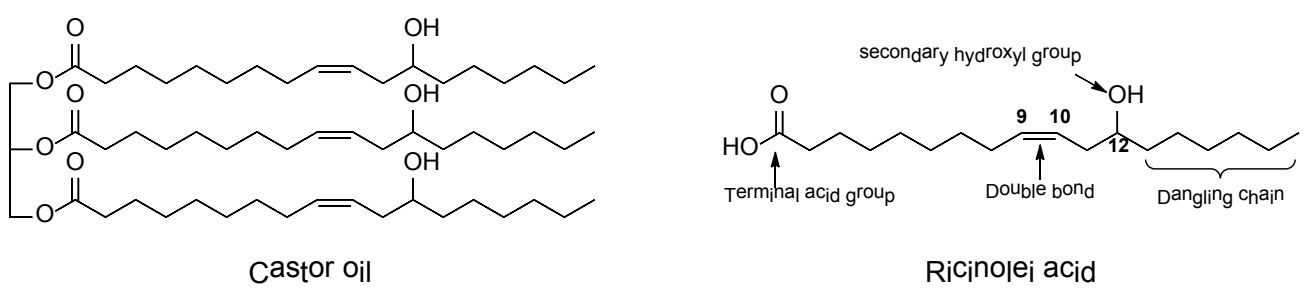

Scheme 17. Structures of castor oil (left) and ricinoleic acid (right)

The presence of hydroxyl groups permits polymerization to prepare polyesters or polyester-anhydrides. The dangling chains as side chains in polymer structures improve hydrophobicity and they influence the mechanical and physical properties of the resulting polymers. These chains act as plasticizers by reducing the glass transition temperatures $\left(T_{\mathrm{g}}\right)$ and prevent crystallization even at very low temperatures [79]. The unique trifunctional castor oil can be considered as triol, which can copolymerize directly with dibasic acid, such as sebacic acid, to form hyperbranched or cross-linked polyesters. Castor oil based copolymerized, hyperbranched or cross-linked polymers have been widely used in biomedical applications, such as drug carrier and tissue engineering scaffold, due to their flexibility, hydrophobicity and injectability [78].

Recently, Domb and Slivniak have reported the preparation of copolyesters based on ricinoleic (RA) and lactic (LA) acids using random condensation polymerization at $150^{\circ} \mathrm{C}$ (Scheme 18a) and transesterification of RA with high molar mass poly(lactic acid) (PLA) followed by thermal polycondensation (Scheme 18b). In the first method, copolyesters P(LA-RA) with molar mass $\left(M_{\mathrm{w}}\right)$ between 2000-8000 $\mathrm{g} \mathrm{mol}^{-1}$ were obtained. Copolyesters with RA content $>20 \%$ were in a liquid state at room temperature. Copolyesters synthesized by transesterification followed by polycondensation with LA/RA ratios of $9: 1$ to $5: 5 \mathrm{w} / \mathrm{w}$ have increased molar mass $\left(M_{\mathrm{w}}\right)$ in the range of 6000-14000 $\mathrm{g} \mathrm{mol}^{-1}$. According to the DSC analysis, only polymers with LA/RA ratio of $9: 1 \mathrm{w} / \mathrm{w}$ showed crystalline property. These liquid polyesters can be used as sealants and as injectable drug carriers [80]. 
In another study of Slivniak et al., copolyesters with molar mass $\left(M_{\mathrm{w}}\right)$ of 5000-16000 $\mathrm{g} \mathrm{mol}^{-1}$ from L-lactide and cyclic RA-based monomer with ratios of $9: 1$ to $5: 5 \mathrm{w} / \mathrm{w}$ were obtained via ROP (Scheme 18c). The ROP was carried out at $150{ }^{\circ} \mathrm{C}$ using $10 \mathrm{wt} \% \mathrm{Sn}(\mathrm{OCOR})_{2}$ as catalyst. The synthesized polymers were off-white solid or semisolid materials $[57,61]$.

a)

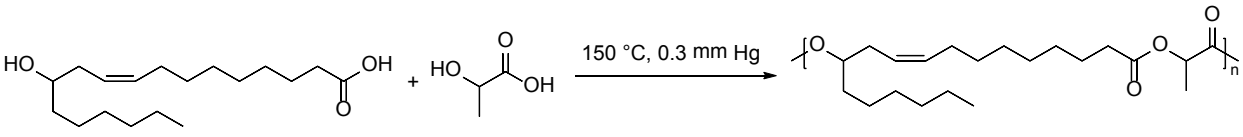

b)

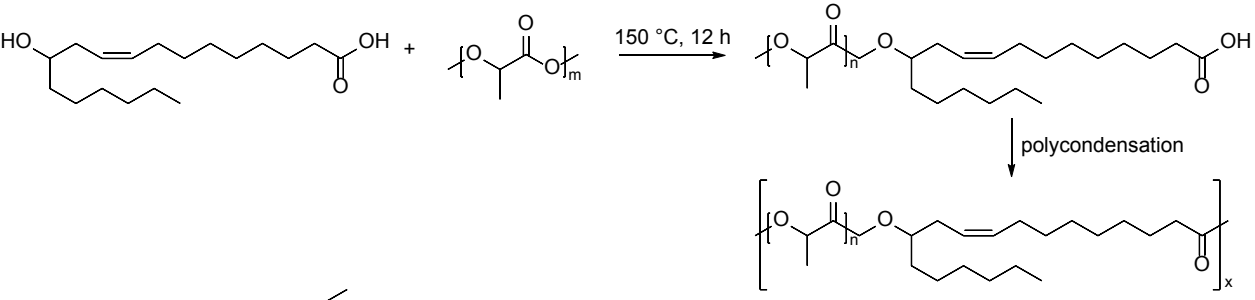

c)

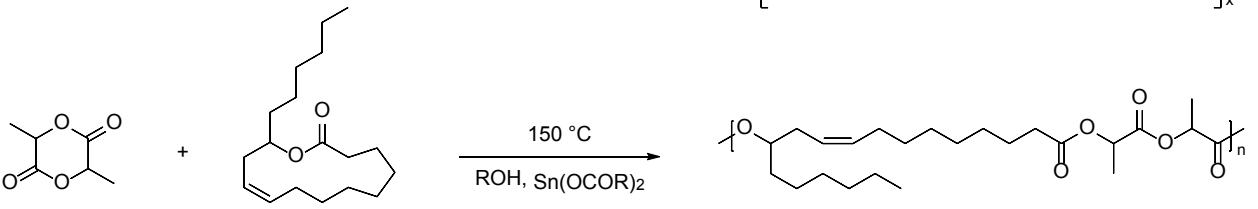

Scheme 18. Synthesis of copolyesters based on RA and LA by a) random thermal polycondensation, $b$ ) transesterification of RA and PLA followed by thermal polycondensation [80] and c) ROP of RA and LA-based lactones $[57,61]$ 


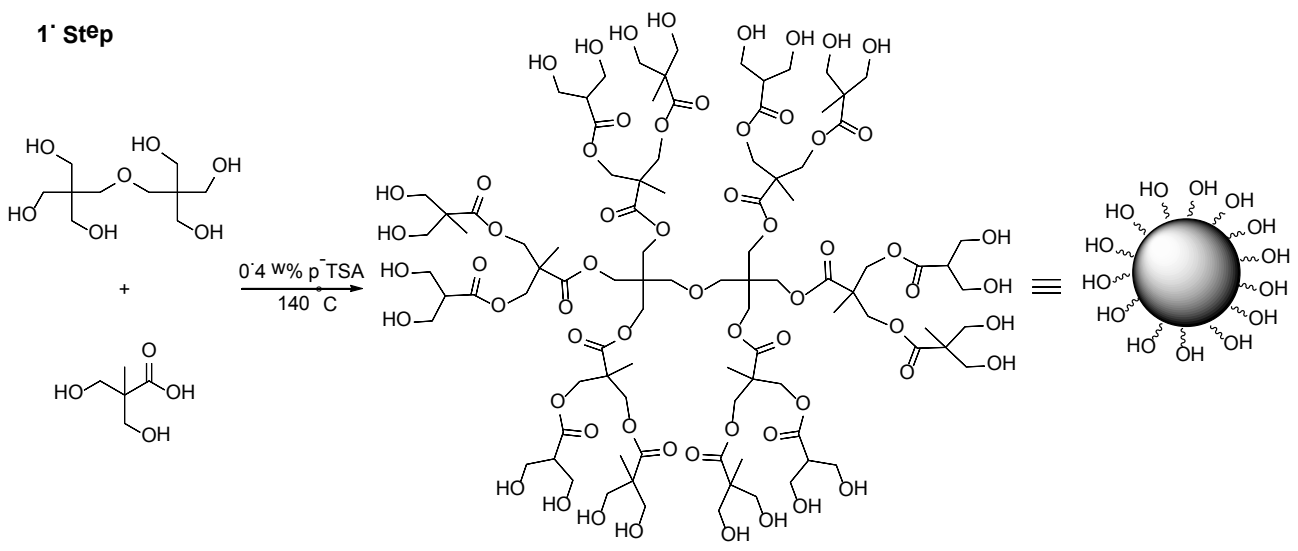

2. Step
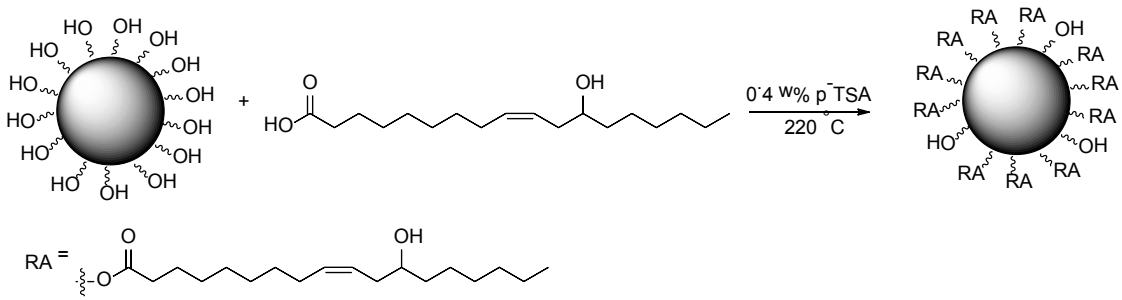

Scheme 19. Synthetic route of ricinoleic acid hyperbranched resin (HBR) [81]

Guc et al. demonstrated a novel ricinoleic acid based HBR for use as drug carrier. In this study, a hyperbranched core with two generations was firstly synthesized from dipentaerythritol and dimethylol propionic acid. The reaction was carried out at $140{ }^{\circ} \mathrm{C}$ using 0.4 wt $\% p$-toluenesulfonic acid ( $p$-TSA) as catalyst (Scheme 19). The core was then esterified with ricinoleic acid at $220^{\circ} \mathrm{C}$ to form the HBR. A number averaged molar mass $\left(M_{\mathrm{n}}\right)$ of $11000 \mathrm{~g} \mathrm{~mol}^{-1}$ with dispersity of 2.11 was obtained for the HBR by GPC analysis. Drug molecules (idarubincin and tamoxifen) can be loaded by hydrogen bonding of unreacted hydroxyl groups in HBR providing controlled delivery [81]. 


\subsection{VEGETABLE OIL BASED POLYANHYDRIDES}

One other important class of biodegradable polymers are polyanhydrides. The anhydride linkages are hydrophobic and water-sensitive. Polyanhydrides based on vegetable oils or fatty acids undergo hydrolytic degradation to form water-soluble small molecules or naturally occurring body components $[82,83]$. Vegetable oils based polyanhydrides are widely used as implantable or injectable drug delivery systems because of their common physicochemical properties, such as biodegradability, biocompatibility, hydrophobicity, flexibility and low melting points [84,85].

Polyanhydrides are usually produced by melt-condensation polymerization of dicarboxylic acid monomers and acetic anhydride to give prepolymers, which can be converted to final polymers in the next step at elevated temperature and under vacuum removing the acetic acid byproduct [83]. Unfortunately, fatty acids are monofunctional and cannot be used for polymerization. To overcome this barrier, oleic acid and erucic acid were dimerized to polymerizable dicarboxylic acid monomers [86]. A serie of copolyanhydrides based on sebacic acid prepolymer and oleic or erucic acid prepolymers with various composition were obtained (Scheme 20a). The homopolymers of oleic acid and erucic acid dimers were viscos liquids, while copolymers with sebacic acid content $>30 \%$ were solid. The melting points $\left(30-70{ }^{\circ} \mathrm{C}\right)$ increased as a function of sebacic acid content [84]. However, according to the in vivo studies in dogs one significant disadvantage of these polyanhydrides was that the degradation products, fatty acid dimers, were not easily metabolized (6 months) in vivo, which was probably attributed to the carbon-carbon linkage between two fatty acids molecules [87].

Domb et al. reported the synthesis of a second class of linear fatty acid based polyanhydrides from ricinoleic acid, sebacic acid and succinic and maleic anhydrides. Ricinoleic acid was firstly acidified with succinic or maleic anhydride to give ricinoleic acid succinate (RAS) and ricinoleic acid maleate (RAM), which was then hydrogenated to 12-hydroxystearic acid succinate (HSAS). After purification of these diacids by column chromatography removing unreacted ricinoleic acid and monofunctional fatty acids, copolymers were synthesized by melt-condensation polymerization of RAS, RAM and HSAS with sebacic acid and acetic anhydride (Scheme 20b). These polymers have molar masses exceeding $50000 \mathrm{~g} \mathrm{~mol}^{-1}$ and melting points below $100^{\circ} \mathrm{C}$ [87-89]. 

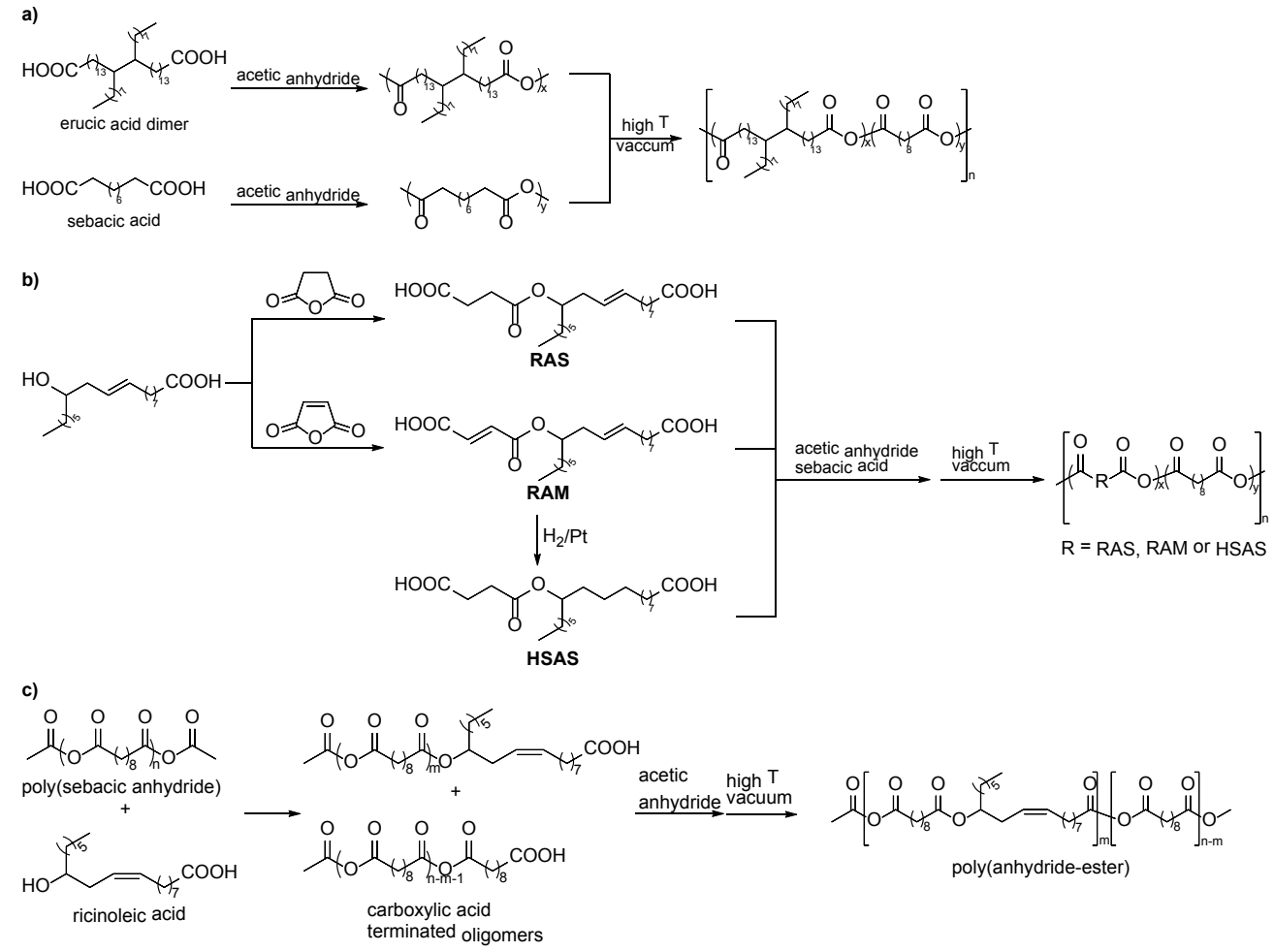

Scheme 20. Synthesis of vegetable oil based polyanhydrides, a) branched polyanhydride from erucic acid dimer and sebacic acid; b) polyanhydrides based on with succinic or maleic anhydride modified ricinoleic acid; c) poly(anhydride-ester) from sebacic and ricinoleic acids.

Poly(anhydride-ester) including two biodegradable bonds in the polymer backbone is a modification of polyanhydrides. These polymers display two degradation stages: water-sensitive anhydride bonds are rapidly cleaved by hydrolysis to polyester prepolymers which have a much slower degradation rate [83]. The incorporation of ester bonds into polyanhydride backbones was achieved by the random reaction of a polyanhydride with the hydroxyl group of ricinoleic acid to form poly(anhydride-ester) oligomers with carboxylic acid end groups. High-molecular weight poly(anhydride-ester) was then prepared by repolymerization of these oligomers at high temperature and under reduced pressure (Scheme 20c) [90,91]. 


\subsection{VEGETABLE OIL BASED POLYESTERAMIDES}

Vegetable oil based polyesteramide resins have been applied in the paint and coating industries. These resins show good water and chemical resistance, low toxicity, adhesion, hardness and gloss properties. In addition, the incorporation of aliphatic and aromatic species in polymer backbones improved significantly the biodegradability and biocompatibility, which are important parameters in biomedical and environmental applications [92-94]. Linseed [92], pongamia glabra [93], Nahar [94] and castor oils [95,96] have been used in the preparation of linear and hyperbranched polyesteramides. The synthesis of vegetable oil based polyesteramide is generally accomplished by condensation polymerization of $N, N$-bis(2-hydroxy ethyl) fatty amides, which were obtained by amidation of fatty acids with diethanolamine, with various dibasic acid or anhydrides (Scheme 21) [95-97].

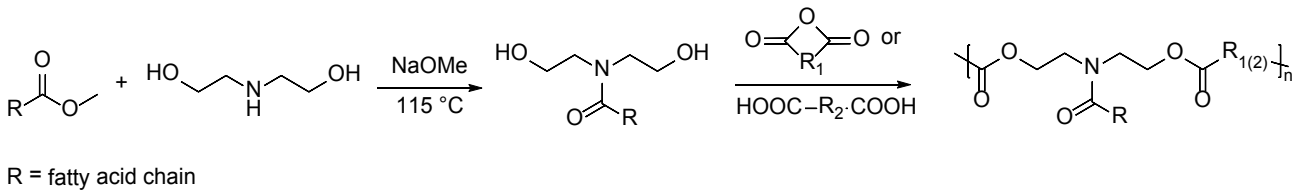

Scheme 21. Synthetic route of vegetable oil based polyesteramides

In one study, biodegradable hyperbranched polyesteramides were prepared with maleic anhydride, phthalic anhydride and isophthalic acid from $\mathrm{N}, \mathrm{N}$-bis(2-hydroxyethyl) ricinoleic fatty amide. The weight average molecular weight of synthesized oligomers was found to be $2300 \mathrm{~g} \mathrm{~mol}^{-1}$ with dispersity of 1.40 . It was observed that the oligomer was soluble in common organic polar solvents, such as dimethyl acetamide (DMAc), dimethyl formamide (DMF), dimethyl sulfoxide (DMSO), methanol and tetrahydrofuran (THF), whereas the oligomer had poor solubility in petroleum ether, diethyl ether and $4 \% \mathrm{NaOH}$ solution. The higher solubility in comparison to linear fatty acid based polyesteramides was attributed to the hyperbranched structure. The properties of the cured polyesteramide thermoset was strongly affected by curing systems. The thermoset cured by epoxy-poly(amido amine) presented better scratch hardness, thermal properties and gloss and chemical resistance than cured by epoxy-cycloaliphatic amine sample. Because of the presence of numerous ester linkages in polymer backbones, the thermoset could be biodegraded using $P$. aeruginosa bacteria. The summarized the fatty acid based thermoset could be potentially used as biodegradable thin film material $[95,96]$. 


\subsection{BIODEGRADATION}

Polymer degradation can be considered as a number of processes, such as physical disintegration, chemical reaction resulting small molecules and degradation by biological mechanisms. Only polymers that can degrade in nontoxic byproducts without causing environmental pollutions can be called biodegradable polymers. The degradation of polymer means cleavage of polymer chains by chemical reaction, while erosion refers to the sum of degradation processes leading to depletion of polymer matrices. Polymer erosions follow mainly two processes: bulk erosion and surface erosion. In bulk erosion, material is lost throughout the polymer volume equally. The erosion rate is independent on the polymer size or shape, only dependent on the polymer volume and decreases during the erosion process. For ideal surface erosion, the degradation occurs from the exterior surface. The total erosion time can be altered by the material shape [98-100].

For many applications, for example drug delivery, surface eroding polymers are preferred since surface erosion is much easier to control and leads to zero-order drug release rate. Surface eroding polymers provides also better protection of the drugs from in vivo degradation than bulk eroding polymers, because water penetration will be retarded. The most common examples for surface eroding polymers are polyanhydrides and poly(ortho esters) [83]. In contrast, bulk erosion is satisfactorily used in other applications that do not require controlled release, such as degradable plastics for packaging. The material can remain intact during use and degrade completely after disposal. For example, the copolyesters poly(lactic/glycolic acid) (PLGA), which is widely used in resorbable sutures and injectable drug delivery systems, displays bulk erosion characteristics [98]. Vegetable oil based biodegradable polymers are mainly referred to polyester and polyanhydride based polymers.

A)
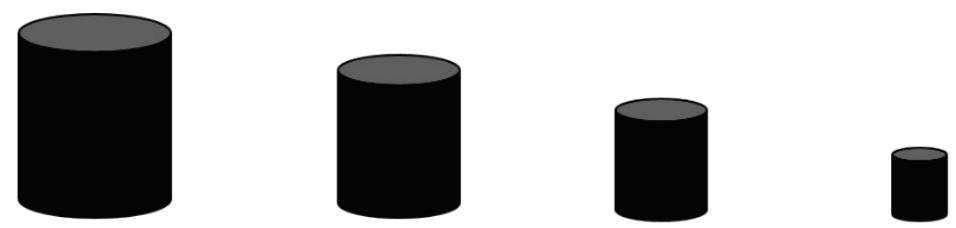

B)
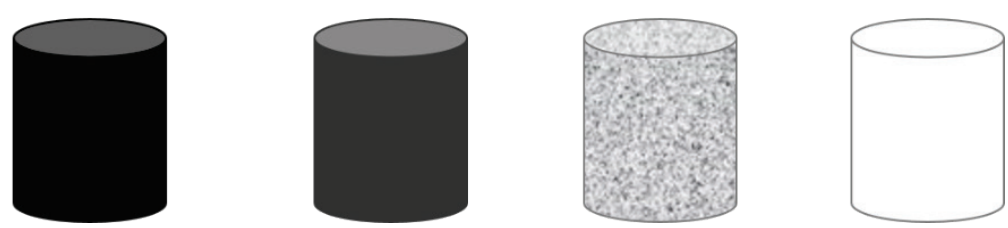

Figure 1. Schematic representation of A) surface erosion and B) bulk erosion 

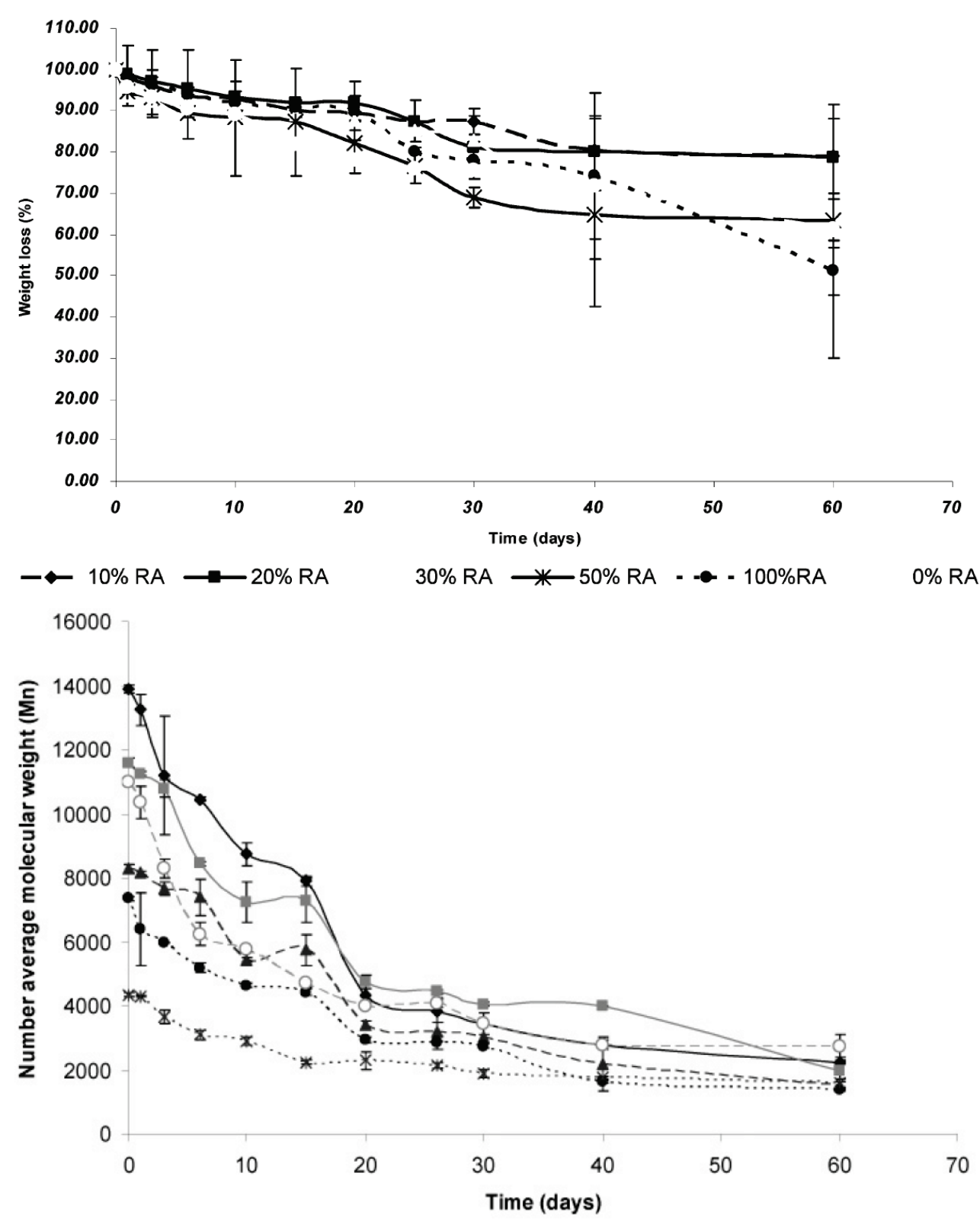

$\longrightarrow 10 \% \mathrm{RA} \longrightarrow-20 \% \mathrm{RA} \quad-₫-30 \% \mathrm{RA} \quad \cdots \bullet \cdot 50 \% \mathrm{RA} \quad \cdots * \cdots 100 \% \mathrm{RA} \quad-0-0 \% \mathrm{RA}$

Figure 2. Investigation of Hydrolysis degradation of P(LA-RA) with different RA content by mention of weight loss (above) and molecular weight loss (below). (Reprinted with permission from Reference 57, Copyright 2005 American Chemical Society)

In the study of Narine et al., both enzymatic and hydrolytic degradation of PNLs from castor oil based monolactone and dilactone were investigated and 
compared with polycaprolactone (PCL). The enzymatic degradation was performed in the presence of Proteinase K for PNL and Pseudomonas cepacia for PCL at $25^{\circ} \mathrm{C}$ in $0.1 \mathrm{M}$ phosphate buffer solution with $\mathrm{pH}=7$. The degradation results showed that PNLs obtained from monolactone had highest degradation rate and reached a weight loss of $80 \%$ in the enzymatic degradation, while PCL and PNLs from dilactone showed $77 \%$ and $45 \%$ weight loss, respectively. In the hydrolytic degradation, PNLs from monolactone showed higher degradation rate $(0.6 \%)$ than PNLs from dilactone $(0.3 \%)$ after 8 days. The difference in degradation rates between PNLs from monolactone and dilactone in both degradation investigations can be correlated to their difference in polymer crystallinity [58]. In the study from Domb et al., the hydrolysis of copolyesters synthesized from lactide (LA) and ricinoleic acid (RA) lactone with w/w ratios from $9: 1$ to $5: 5$ was investigated by monitoring of weight loss and molecular weight loss. As shown in Figure 2, all polymers lost 20-40\% weight with constant degradation rates after 60 days incubation. The number averaged molecular weight $\left(M_{\mathrm{n}}\right)$ monitered by gel permeation chromatography (GPC) decreased quickly to about $4000 \mathrm{~g} \mathrm{~mol}^{-1}$ during the first 20 days, followed by a slow degradation for another 40 days. The copolyesters maintained their integrity during the hydrolysis investigation and showed bulk erosion characteristics [58]. In another study of this group, copolyesters $\mathrm{P}(\mathrm{LA}-\mathrm{RA})$ with $60: 40 \mathrm{w} / \mathrm{w}$ was prepared by condensation polymerization, transesterification and ring opening polymerization. In comparison among the P(LA-RA) prepared by the three methods, all samples had about $20 \%$ weight loss after 60 days not depending on synthesis methods [61].

As mentioned above, polyanhydrides are known as a class of pure surface eroding biodegradable polymers. The anhydride bonds are highly hydrophobic and hence are believed to prevent water penetration into the polymer matrix. Only the labile anhydride bonds on the surface can be hydrolyzed and convert to two carboxylic acids in water medium. Hydrolytic degradation rate of polyanhydride depends on $\mathrm{pH}$ and solubility of the degradation byproducts [101].

To identify the erosion type of fatty acid based polyanhydride, poly(fatty acid dimer:sebacic acid; FAD-SA, 50:50 w/w) was investigated by Shah etal. In this study, water uptake was investigated into cylinder and disk-shaped devices of

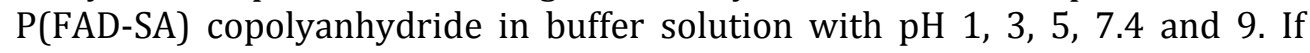
$\mathrm{P}(\mathrm{FAD}-\mathrm{SA})$ is hydrolyzed by pure surface erosion, water should not be found in the polymer bulk. At $\mathrm{pH} 1-5$, there was no significant difference in the water uptake rate. Only about $5 \%(\mathrm{v} / \mathrm{v})$ water was taken up into cylinder shaped devices under these $\mathrm{pH}$ conditions after 4 weeks incubation. In contrast, at $\mathrm{pH}$ 7.4 and 9, approx. two-fold water uptake to $8-9 \%(\mathrm{v} / \mathrm{v})$ was obtained. The same investigation for disk-shaped devices showed similar water uptake of about $4 \%$ at $\mathrm{pH} 1-5$. However, at $\mathrm{pH} 7.4$ and $9,15-20 \%(\mathrm{v} / \mathrm{v})$ water uptake was observed in 2 weeks and was directly proportional to the surface area to 
volume ratio $(\mathrm{SA} / \mathrm{V})$ of disk-shaped device compared to that of the cylindrical device $(3.27: 1)$. Combining the observation by photomicrography and the large amount of water penetration found in devices, the hydrolysis investigation reveal that the P(FAD-SA) device was not undergoing pure surface erosion at $\mathrm{pH} 7.4$ and 9 [102]. As is well-known, polyanhydrides are mainly used as drug carrier. The correlation between drug release rate with erosion rate of polymer matrix was investigated in another study of Shah etal. As model compounds, highly water soluble mannitol $\left(\mathrm{M}=182 \mathrm{~g} \mathrm{~mol}^{-1}\right)$, moderately water soluble inulin $\left(\mathrm{M}=5000 \mathrm{~g} \mathrm{~mol}^{-1}\right)$ and lipophilic stearic acid $\left(\mathrm{M}=284 \mathrm{~g} \mathrm{~mol}^{-1}\right)$ were incorporated into disk-shaped P(FAD-SA) copolyanhydride device. The results showed that the hydrolytic degradation of $\mathrm{P}(\mathrm{FAD}-\mathrm{SA})$ is $\mathrm{pH}$-dependent. At $\mathrm{pH}$ 9, the degradations of all the devices proceeded 8-10 times faster than that at $\mathrm{pH} 1-5$ and 1.3-2 times faster than at pH 7.4. The pH-dependent property could be explained by the base sensitive anhydride bond and higher solubility of degradation products resulting in rapid diffusion and dissolution out of the devices. In contrast, the degradation products, fatty acid dimer and sebacic acid, were unionized and insoluble in buffer solution at lower $\mathrm{pH}$. Hence, water penetration into polymer matrix was blocked by forming a barrier from insoluble degradation products. Incorporation of water-soluble compounds into devices accelerated degradation rates at all $\mathrm{pH}$, because the water-soluble compounds were rapidly released and created pores and channels in the devices resulting in water penetration into devices. In contrast, poorly water-soluble stearic acid retarded the degradation rate at all $\mathrm{pH}$, except at $\mathrm{pH} 9$ due to the enhanced water-solubility resulted from ionization of stearic acid at higher $\mathrm{pH}$ [103]. Another degradation study for P(RAM-SA) (Scheme 20b) by Kumar etal. suggested similarly, that the fatty acid based polyanhydride degradation is not undergoing pure surface erosion [104]. In conclusion, the erosion of fatty acid based polyanhydride is a complex process depending on water uptake, bond cleavage, property of loading compounds and $\mathrm{pH}$ of the hydrolysis medium.

\subsection{APPLICATION}

\subsubsection{Controlled drug delivery system}

Controlled drug delivery systems are one of the fastest growing areas of science and refers to transport a pharmaceutical compound in humans or animals to safely achieve a desired therapeutic effect. Developing novel drug delivery systems aim to reduce treatment toxicity and improve efficacy, such as increasing therapeutic activity and avoiding frequently repeated injections. As shown in Figure 3a, in temporal control, a drug is released over an extended duration, while in traditional injections drugs are rapidly metabolized and eliminated from the body. Figure $3 \mathrm{~b}$ represents the benefit of distribution controlled drug release system. In distribution control, drugs are required to 
be delivered at the precise active site within the body to increase the drug concentration at site of action and maintain the systemic drug concentration in a safe area to avoid causing side effects [83].

The following key conditions must be met if any polymeric material is designed to use for drug delivery application [90]:

- good biocompatibility of polymeric material and its degradation products;

- high hydrophobicity for controlled drug release;

- degraded and metabolized completely from the body after implantation;

- low melting point (normally $<100^{\circ} \mathrm{C}$ ) and good solubility in common organic solvents for device fabrication;

- high flexibility, not broken during use and degradation;

- low cost.

The vegetable oil based polymers satisfy all above properties and thus can be used as drug carrier. Moreover, it is observed that the incorporation of vegetable oil moieties in polymers can enhance the biodegradation and provides a better control over drug release $[12,90]$. A series of vegetable based polyanhydrides, polyesters and their copolymers were developed and applied as drug carrier for anticancer drugs, local anesthetics, antibiotics and large molecule biological drugs (e.g. proteins, peptides, hormones etc.) [58,61,80,84,86-91,104-107]. Poly(ester anhydride) based on sebacic acid and ricinoleic acid P(SA:RA) demonstrated injectable properties. The polymers with SA:RA ratios of $3: 7,2.5: 7.5$ and $2: 8(\mathrm{w} / \mathrm{w})$ were pasty and suitable for injection at $37^{\circ} \mathrm{C}$. After injection the polymer was solidified by a mechanism of in situ gelling organogels. According to the in vivo toxicity test, the polymer was nontoxic. Hence, this polymer could be used as injectable drug carrier for anticancer drug paclitaxel. In vitro drug release investigation showed, that drug was released for months [91,105-107]. Furthermore, hyperbranched polymers based on vegetable oils were as well evaluated for their degradation and drug release properties [81,82]. 

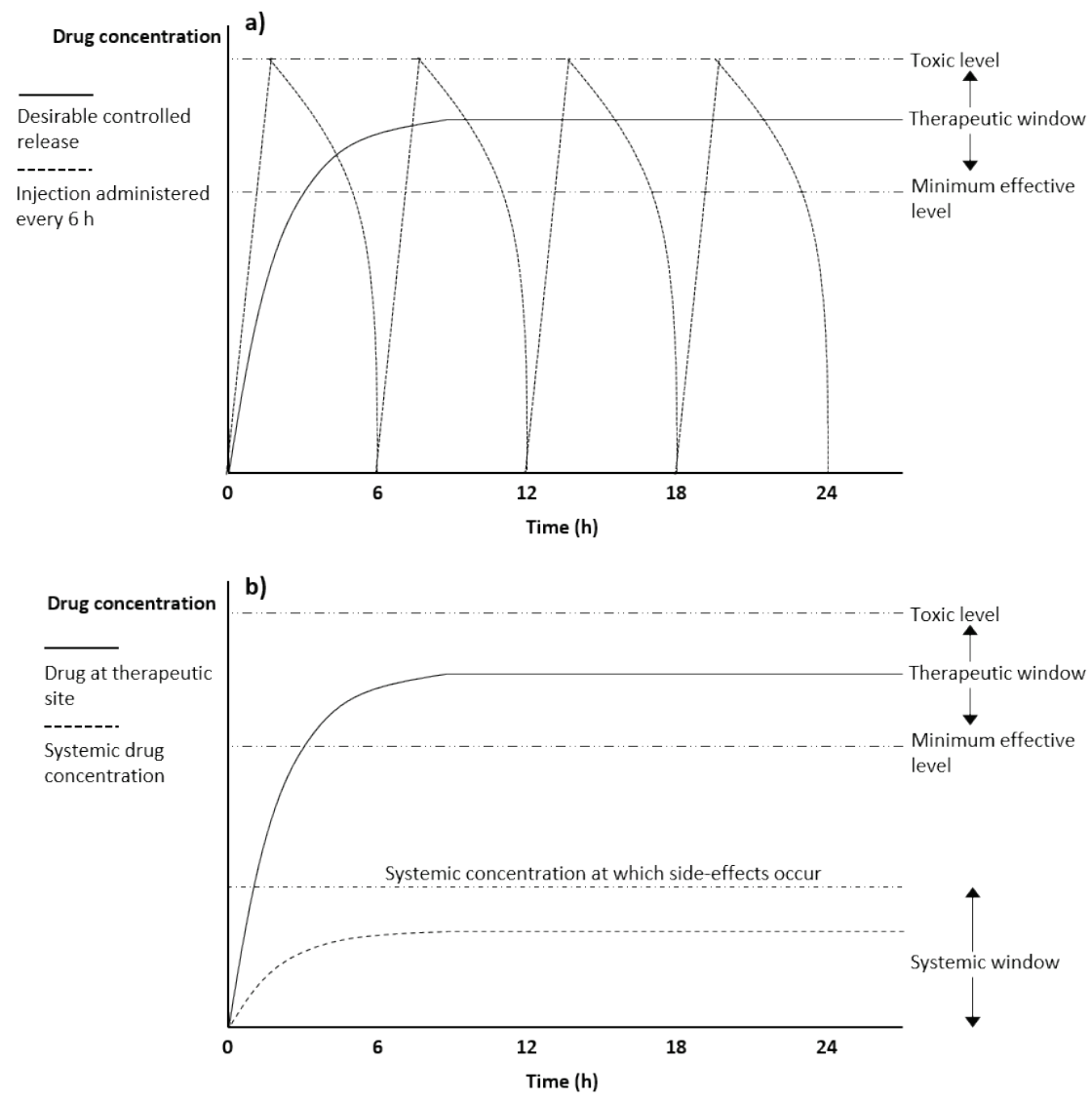

Figure 3. Schematic representation of controlled drug release: a) temporal control and b) distribution control. (Reproduced with permission from Reference 83, Copyright 1999 American Chemical Society)

\subsubsection{Tissue engineering}

Tissue engineering is an interdisciplinary field of engineering, life science and material sciences, and aims to regenerate or replace biological damaged tissues or generate replacement organs. Due to the biodegradable, biocompatible and versatile properties, vegetable oil based polymeric materials can be viewed as good candidate for tissue engineering. For example, poly(glycerol sebacate)ester based on sebacic acid and glycerol, which both are endogenous compounds in human metabolism, has been used in soft tissue engineering applications for repair of retina, nerve, vessel and myocardium. To study the in vitro fibroblast response and degradation, these polymers demonstrated satisfactory biocompatibility and biodegradation. Hard materials based on soybean oil and sunflower oil were as well investigated and showed cell adhesion and proliferation natures. However, most of these 
materials are based on non-degradable urethane cross-linked polymers [9]. Hence, an ideal cross-linked elastomer should be prepared from low toxic and in vivo metabolizable raw materials and additives (such as initiator, catalyst and solvent). Moreover, the used cross-linked polymeric materials should be biodegradable. Phosphoester cross-linked vegetable oil elastomers were prepared recently by Zhu etal. and meet all above principles. Investigations in vivo and invitro confirm that the materials have good elasticity, biocompatibility and biodegradability, indicating potential applications in bone tissue engineering [108].

\subsubsection{Coating}

Vegetable oils have been used as binder or additives in paints and coatings for a long time, even as constituent in coatings during the days of cave painting. In the last decades, vegetable oil based polyesters (alkyds), polyesteramides, polyetheramides and polyurethanes have been extensively investigated in coating applications. These coatings are available for specific uses due to their biocompatible, biodegradable and highly hydrophobic properties. However, the long aliphatic hydrophobic chains in the oil structure often lead to low mechanical strength, lack toughness and water insolubility $[9,97]$. An example of biodegradable castor oil based polyesteramide for coating application was reported by Karaketal. They found that the coorperation of the ester and amide moieties in polymer backbone enhances the mechanical and thermal properties. The ester bonds could be degraded in the presence of lipase. The obtained adhesion strength, abrasion resistance, scratch hardness, gloss, impact strength and mechanical properties suggest applications in polymeric surface coatings $[95,96]$.

\subsection{CONCLUSIONS}

Enter 21st century, resource and environmental problems have puzzled the world economic development. With the reduction of energy, the use of vegetable oils and fatty acids derived from them as environment friendly and renewable raw materials for manufacturing polymeric materials in many different fields has become the hotspot of study. Different types of biodegradable polymers such as polyesters, polyanhydrides, polyesteramides and poly(ester anhydrides) have been produced from the vegetable platform. These polymers were mainly used for biomedical applications such as drug delivery system and tissue engineering. The aim of this chapter was firstly to highlight the conversion of vegetable oils to suitable monomers for production of biodegradable polymeric materials. Secondly, the recent progress in the synthetic strategies of polymeric materials from vegetable oils and fatty acids, their biodegradation process and applications were reviewed. Overall, the biodegradable polymeric materials prepared from vegetable oils offer a wide 
range of biomaterials with different properties. Some of these polymers exihibited excellent biocompatibilities, biodegradations and thermal and mechanical properties. To control these properties can be accomplished by simply changing the comonomer compositions.

\section{REFERENCES}

1. Y. Xia, R.C. Larock. Green Chem. 12 (2010) 1893.

2. J.O.M. Marco Eissen, E. Schmidt, U. Schneidewind. Angew. Chem. Int. Ed. 41 (2002) 414-436.

3. C. Williams, M. Hillmyer. Polym. Rev. 48 (2008) 1-10.

4. S. Miao, P. Wang, Z. Su, S. Zhang. Acta Biomater. 10 (2014) 1692-1704.

5. L. Montero de Espinosa, M.A.R. Meier. Eur. Polym. J. 47(2011) 837-852.

6. S. Li. Agricultural Outlook (2016) 36-39.

7. Food and Agriculture Organization of the United Nations: Food Outlook Biannual Report on Global Food Markets, 2016.

8. $\quad$ M.R. Islam, M.D.H. Beg, S.S. Jamari. Polym. Rev. 131 (2014) 40787.

9. G. Lligadas, J.C. Ronda, M. Galià, V. Cádiz. Mater. Today 16 (2013) 337-343.

10. N. Karak, Vegetable oil-based polymers: Properties, processing and applications, Woodhead Publishing Limited, Cambridge, 2012.

11. M.N. Belgacem, A. Gandini. Monomers, Polymers and Composites from Renewable Resources, Elsevier, Amsterdam, 2008.

12. C.V. Stevens, R. Verhé, Renewable Bioresources: Scope and Modification for Non-food Applications, John Wiley \& Sons, West Sussex, 2004.

13. N.O.V. Sontag. J. Am. Oil Chem. Soc. 59 (1982) 795A-802A.

14. E. Can, S. Küsefoğlu, R.P. Wool. J. Appl. Polym. Sci. 81 (2001) 69-77.

15. E. Can, R.P. Wool, S. Küsefoğlu. J. Appl. Polym. Sci. 102 (2006) 1497-1504.

16. O. Saravari, P. Phapant, V. Pimpan. J. Appl. Polym. Sci. 96 (2005) 1170-1175.

17. A. Campanella, L.M. Bonnaillie, R.P. Wool. J. Appl. Polym. Sci. 112 (2009) 2567-2578.

18. V.C. Patel, J. Varughese, P.A. Krishnamoorthy, R.C. Jain, A.K. Singh, M. Ramamoorty. J. Appl. Polym. Sci. 107 (2008) 1724-1729.

19. I.O. Igwe, O. Ogbobe. J. Appl. Polym. Sci. 75 (2000) 1441-1446.

20. S. Tiwari, S. Tiwari. J. Appl. Polym. Sci. 114 (2009) 2648-2654.

21. N. Dutta, N. Karak, S.K. Dolui. Prog. Org. Coat. 58 (2007) 40-45.

22. N. Dutta, N. Karak, S.K. Dolui. Prog. Org. Coat. 49 (2004) 146-152.

23. L.I. Smith, F.L. Greenwood, O. Hudrlik. Org. Synth. 26 (1946) 63.

24. J.M. Churc, F.C. Whitmor, R.V. Mcgrew. J. Am. Chem. Soc. 56 (1933) 176-184.

25. V.I. Gibalov, G.J. Pietsch. Ozone-Sci. Eng. 28 (2006) 119-124.

26. D. Graiver, M. Patil, R. Narayan. Recent Pat. Materials Sci. 3 (2010) 203-218.

27. U. von Gunten. Water Res. 37 (2003) 1443-1467.

28. J. Sadowska, B. Johansson, E. Johannessen, R. Friman, L. Broniarz-Press, J.B. Rosenholm. Chem. Phys. Lipids 151 (2008) 85-91.

29. C.E. Bishop, P.R. Story. J. Am. Chem. Soc. 90 (1968) 1905-1907.

30. R. Bruckner, Organic Mechanisms: Reactions, Stereochemistry and Synthesis, Springer-Verlag, Berlin Heidelberg, 2010.

31. R.L. Kuczkowski. Chem. Soc. Rev. 21 (1992) 79-83.

32. C.D. Harries. Liebigs Ann. Chem. 343 (1905) 311-344. 
33. S. Fliszar, J. Carles. J. Am. Chem. Soc. 91 (1969) 2637-2643.

34. T.S. Omonov, E. Kharraz, J.M. Curtis. J. Am. Oil Chem. Soc. 88 (2010) 689-705.

35. X. Kong, S.S. Narine. Biomacromolecules 8 (2007) 2203-2209.

36. I. Cvetkovic, J. Milic, M. Ionescu, Z. Petrovic. Hemijska Industrija 62 (2008) 319-328.

37. Z.S. Petrovic, W. Zhang, I. Javni. Biomacromolecules 6 (2005) 713-719.

38. E.H. Pryed, D.E. Anders, H.M. Teeter, J.C. Cowan. J. Am. Oil Chem. Soc. 38 (1961) 375-379.

39. A. Biswas, H.N. Cheng, K.T. Klasson, Z. Liu, J. Berfield, F.O. Ayorinde. J. Am. Oil Chem. Soc. 91 (2014) 2111-2116.

40. L.H. Sperling, J.A. Manson. J. Am. Oil Chem. Soc. 60 (1983) 1887-1892.

41. V. Kolot, S. Grinberg. J. Appl. Polym. Sci. 91 (2003) 3838-3843.

42. U. Biermann, W. Friedt, S. Lang, W. Lühs, G. Machmüller, J.O. Metzger, M.R.G. Klaas, H.J. Schäfer, M.P. Schneider. Angew. Chem. Int. Ed. 39 (2000) 2206-2224.

43. U. Biermann, U. Bornscheuer, M.A. Meier, J.O. Metzger, H.J. Schafer. Angew. Chem. Int. Ed. 50 (2011) 3854-3871.

44. J. Lu, S. Khot, R.P. Wool. Polymer 46 (2005) 71-80.

45. H. Bakhshi, H. Yeganeh, S. Mehdipour-Ataei, A. Solouk, S. Irani. Macromolecules 46 (2013) 7777-7788.

46. R. Chen, J.S. Chen, C. Zhang, M.R. Kessler. RSC Adv. 5 (2015) 1557-1563.

47. G. Guo, J. Sun, C. Zhao, Y. Liu, C.-M. Liu. Green Chem. 18 (2016) 1278-1286.

48. Z. Chen, B.J. Chisholm, R. Patani, J.F. Wu, S. Fernando, K. Jogodzinski, C.D. Webster. J. Coat. Technol. Res. 7 (2010) 603-613.

49. S.W. Choi, D. Wan Seo, Y. Don Lim, Y. Gi Jeong, M.S. Islam Mollah, H. Park, T. Whan Hong, W. Gi Kim. J. Appl. Polym. Sci. 121 (2011) 764-769.

50. S.N. Khot, J.J. Lascala, E. Can, S.S. Morye, G.I. Williams, G.R. Palmese, S.H. Kusefoglu, R.P. Wool. J. Appl. Polym. Sci. 82 (2001) 703-723.

51. A. Guo, Y. Cho, Z.S. Petrovic. J. Polym. Sci, Part A: Polym. Chem. 38 (2000) 3900-3910.

52. H. Bakhshi, H. Yeganeh, S. Mehdipour-Ataei. J. Biomed. Mater. Res. A 101 (2013) 1599-1611.

53. M. Jalilian, H. Yeganeh, M.N. Haghighi. Polym. Int. 57 (2008) 1385-1394.

54. M.S.F. Lie Ken Jie, M.S.K. Syed-Rahmatullah. J. Am. Oil Chem. Soc. 69 (1992) 359-362.

55. $\quad$ M.S.F. Lie Ken Jie, Y.F. Zheng. Chem. Phys. Lipids 49 (1988) 167-178.

56. G. Liu, X. Kong, H. Wan, S. Narine. Biomacromolecules 9 (2008) 949-953.

57. R. Slivniak, A.J. Domb. Biomacromolecules 6 (2005) 1679-1688.

58. S. Abraham, S.S. Narine. J. Polym. Sci, Part A: Polym. Chem. 47 (2009) 6373-6387.

59. C. Bartolini, L. Mespouille, I. Verbruggen, R. Willem, P. Dubois. Soft Matter 7 (2011) 9628.

60. S. Tempelaar, L. Mespouille, O. Coulembier, P. Dubois, A.P. Dove. Chem. Soc. Rev 42 (2013) 1312-1336.

61. R. Slivniak, A. Ezra, A.J. Domb. Pharm. Res. 23 (2006) 1306-1312.

62. F. Suriano, O. Coulembier, J.L. Hedrick, P. Dubois. Polym. Chem. 2 (2011) 528-533. 
63. B.G.G. Lohmeijer, R.C. Pratt, F. Leibfarth, J.W. Logan, D.A. Long, A.P. Dove, F. Nederberg, J. Choi, C. Wade, R.M. Waymouth, J.L. Hedrick. Macromolecules 39 (2006) 8574-8583.

64. C. Thomas, B. Bibal. Green Chem. 16 (2014) 1687-1699.

65. J. Sun, D. Kuckling. Polym. Chem. 7 (2016) 1642-1649.

66. A. Pascual, J.R. Leiza, D. Mecerreyes. Eur. Polym. J. 49 (2013) 1601-1609.

67. K. Makiguchi, Y. Ogasawara, S. Kikuchi, T. Satoh, T. Kakuchi. Macromolecules 46 (2013) 1772-1782.

68. D. Delcroix, B. Martín-Vaca, D. Bourissou, C. Navarro. Macromolecules 43 (2010) 8828-8835.

69. A.M. Goldys, D.J. Dixon. Macromolecules 47 (2014) 1277-1284.

70. T.K. Sen, S. Sau, A. Mukherjee, A. Modak, S.K. Mandal, D. Koley. Chem. Commun. 47 (2011) 11972-11974.

71. P.U. Naik, K. Refes, F. Sadaka, C.-H. Brachais, G. Boni, J.-P. Couvercelle, M. Picquet, L. Plasseraud. Polym. Chem. 3 (2012) 1475.

72. A.P. Dove, R.C. Pratt, B.G.G. Lohmeijer, R.M. Waymouth, J.L. Hedrick. J. Am. Chem. Soc. 127 (2005) 13798-13799.

73. M.A. Bertucci, S.J. Lee, M.R. Gagne. Chem. Commun. 49 (2013) 2055-2057.

74. K.S. Bisht, Y.Y. Svirkin, L.A. Henderson, R.A. Gross. Macromolecules 30 (1997) 7735-7742.

75. J.W. Peeters, O.V. Leeuwen, A.R.A. Palmans, E.W. Meijer. Macromolecules 38 (2005) 5587-5592.

76. S. Kobayashi. Macromol. Rapid Commun. 30 (2009) 237-266.

77. B. De, K. Gupta, M. Mandal, N. Karak. ACS Sustain. Chem. Eng. 2 (2014) 445-453.

78. K.R. Kunduru, A. Basu, M. Haim Zada, A.J. Domb. Biomacromolecules 16 (2015) 2572-2587.

79. Z.S. Petrović, I. Cvetković, D. Hong, X. Wan, W. Zhang, T. Abraham, J. Malsam. J. Appl. Polym. Sci. 108 (2008) 1184-1190.

80. R. Slivniak, A.J. Domb. Macromolecules 38 (2005) 5545-5553.

81. E. Guc, G. Gunduz, U. Gunduz. Drug Dev. Ind. Pharm. 36 (2010) 1139-1148.

82. C. Lluch, G. Lligadas, J.C. Ronda, M. Galia, V. Cadiz. Macromol. Rapid Commun. 32 (2011) 1343-1351.

83. K.E. Uhrich, S.M. Cannizzaro, R.S. Langer, K.M. Shakesheff. Chem. Rev. 99 (1999) 3181-3198.

84. A.J. Domb, M. Maniar. J. Polym. Sci, Part A: Polym. Chem. 31 (1993) 1275-1285.

85. M. Sokolsky-Papkov, A. Shikanov, A. Ezra, B. Vaisman, A.J. Domb. Bull. Israel Chem. Soc. 1004 (2009) 60-69.

86. Y. Tabata, S. Gutta, R. Langer. Pharm. Res. 10 (1993) 487-496.

87. D. Teomim, A. Nyska, A.J. Domb. J. Biomed. Mater. Res. 45 (1999) 258-267.

88. A.J. Domb, R. Nudelman. J. Polym. Sci, Part A: Polym. Chem. 33 (1995) 717-725.

89. D. Teomim, A.J. Domb. J. Polym. Sci, Part A: Polym. Chem. 37 (1999) 3337-3344.

90. J.P. Jain, M. Sokolsky, N. Kumar, A.J. Domb. Polym. Rev. 48 (2008) 156-191.

91. M.Y. Krasko, A. Shikanov, A. Ezra, A.J. Domb. J. Polym. Sci, Part A: Polym. Chem. 41 (2003) 1059-1069.

92. S. Ahmad, S.M. Ashraf, F. Zafar. J. Appl. Polym. Sci. 104 (2007) 1143-1148.

93. S. Ahmad, S.M. Ashraf, F. Naqvi, S. Yadav, A. Hasnat. Prog. Org. Coat. 47 (2003) 95-102. 
94. S.S. Mahapatra, N. Karak. Prog. Org. Coat. 51 (2004) 103-108.

95. S. Pramanik, R. Konwarh, K. Sagar, B.K. Konwar, N. Karak. Prog. Org. Coat. 76 (2013) 689-697.

96. S. Pramanik, K. Sagar, B.K. Konwar, N. Karak. Prog. Org. Coat. 75 (2012) 569-578.

97. E. Sharmin, F. Zafar, D. Akram, M. Alam, S. Ahmad. Ind. Crops Prod. 76 (2015) 215-229.

98. J.A. Tamada, R. Langer. Proc. Nadl. Acad. Sci. USA 90 (1997) 552-556.

99. A. Giipferich. Biomater. 18 (1997) 397-403.

100. A. Gdpferich, R. Langer. Macromolecules 26 (1993) 4105-4112.

101. E.-S. Park, M. Maniarb, J.C. Shaha. J. Control. Release 48 (1997) 67-78.

102. E.-S. Park, M. Maniar, J. Shah. J. Control. Release 40 (1996) 55-65.

103. E.-S. Park, M. Maniar, J. Shah. J. Control. Release 40 (1996) 111-121.

104. J.P. Jain, S. Modi, N. Kumar. J. Biomed. Mater. Res. A 84 (2008) 740-752.

105. A. Shikanov, B. Vaisman, M.Y. Krasko, A. Nyska, A.J. Domb. J. Biomed. Mater. Res. A 69A (2004) 47-54.

106. A. Shikanov, A. Ezra, A.J. Domb. J. Control. Release 105 (2005) 52-67.

107. A. Shikanov, A.J. Domb. Biomacromolecules 7 (2006) 288-296.

108. Z. Liu, Y. Xu, L. Cao, C. Bao, H. Sun, L. Wang, K. Dai, L. Zhu. Soft Matter 8 (2012) 5888-5895. 